\title{
Opciones fundamentales en las Ciencias Sociales
}

\author{
ESQUEMA
}

I. INTRODUCCIÓN

II. DesarRollo

1. Una opción por un futuro prometedor:

1.1. La dialéctica hegeliana en la teleología marxista.

1.2. FROMM: voluntad positiva para humanizar.

2. El elemento negativo en el análisis de la sociedad:

2.1. FREUD: la reducción al impulso.

2.2. La Escuela de Frankfurt: el pesimismo práctico.

\section{CONCLUSIÓN}

1. El sentido de los datos.

2. La crítica de las ideologías.

3. El peligro del dogmatismo.

4. La importancia de la reflexión filosófica sobre las ciencias sociales y sus métodos. 
«A mi Familia»

\section{INTRODUCCIÓN}

1. La presencia de presupuestos teóricos en el razonamiento científico.

A leer un libro, la prensa o ver la televisión, observamos una gran disparidad de criterios, la seguridad con que se realizan afirmaciones 'absolutas', y el desparpajo con que se critica la teoría o hipótesis del contrario. Al salir a la calle y hablar con nuestros vecinos nos damos cuenta de cómo cada uno construye su propia idea de la realidad, ensambla 'su' mundo y acaba, en la mayor parte de los casos, por hacerlo inamovible ( $\mathrm{y}$, cuanto más inamovible, más seguro). En este mare magnum de opiniones contrarias, de posibles soluciones a problemas sociales y económicos de carácter tan opuesto que hacen dudar de su 'procedencia' (si son reflejo de ideas o de la realidad social formulada en ideas), utilizamos los conceptos y las teorías de los clásicos del pensamiento para explicarnos y para configurar nuestro mundo: términos como alienación, inconsciente, cultura económica, crisis de mercado, tecnología de la información, etc., nos remiten a los autores que los desarrollaron, a la vez que su uso configura (en mayor o menor medida, dependiendo de la capacidad crítica de cada individuo) nuestro razonamiento, nuestra visión de las cosas.

Utilizamos ciertos conceptos para acercarnos a la realidad y para reflexionar sobre ella... El origen de este trabajo se sitúa en la pregunta por tales conceptos $\mathrm{u}$ opiniones previas: ¿Hasta qué punto condicionan y configuran nuestro análisis de la realidad? Pero..., no sólo nos preguntamos por el pensamiento cotidiano; la pregunta por los 'conceptos previos' es aplicable a los autores que los introducen en el pensamiento colectivo: ¿Hasta qué punto las teorías de autores como Marx o Freud se estructuran en torno a ciertos conceptos o ideas generales que orientan su modo de ver las cosas y las propuestas últimas de su raciocinio?

Nos planteamos, en definitiva, la pregunta por la estructura básica de nuestra reflexión, y la influencia que ejercen en ella las ideas previas desde las cuales atisbamos la realidad. Este análisis es importante cuando nos paramos a pensar en el status de nuestros razonamientos: la mayoría de los supuestos sobre los que construimos nuestras ideas no son 'demostrables', no son 'verdades' absolutas, con exclusividad de otras verdades contrarias. Por eso es fundamental analizar la dependencia de nuestro pensar de esas 'opciones previas', conceptos básicos que estructuran nuestra concepción del mundo, del ser y del actuar.

Esta 'necesidad' no surge de la mera especulación o de la nada: a partir de las investigaciones de Hanson y Kuhn, los científicos han tomado conciencia de la importancia de los 'paradigmas' (en el sentido amplio de matriz discipli- 
nar) ${ }^{1}, \mathrm{y}$ del grado en que su formación y sus conocimientos previos dirigen su investigación. En los autores fundamentales en las Ciencias Sociales, y en general en el pensamiento contemporáneo (como Popper, Habermas, Freud o Parsons) observamos cómo una gran parte de sus razonamientos metodológicos y de contenido obedecen a una concepción previa de las cosas y del conocimiento científico. También ellos estructuran sus razonamientos en torno a claves previas, no demostrables científicamente. Analizar el status de las mismas es importante, porque con ello quedaríamos a salvo del dogmatismo y los excesos cometidos en nombre de la supuesta verdad absoluta de las teorías de algunos autores... La pregunta es muy sencilla: ¿es posible encontrar en los autores clave, aquellos que han dado inicio a las corrientes más importantes de las Ciencias Sociales, esos elementos que diseñan, configuran y explican las consecuencias últimas de su pensamiento?

Si podemos hacer explícitas esas líneas centrales, podremos comprender mejor sus análisis y los límites y posibilidades de desarrollo de las escuelas que se fundan en ellos. Entenderemos por qué autores como Marx tomaron ciertas posturas de forma casi necesaria a partir de los supuestos implícitos de su razonamiento, y cómo a veces las consecuencias de los esquemas de pensamiento y análisis de la realidad desfiguran las intuiciones y valores aportados por la idea inicial. Es evidente que tanto el positivismo lógico como el lenguaje objetivista de la física responden a una toma de postura previa... Habermas expresa correctamente esta situación al analizar la negación de la autorreflexión del conocimiento que efectúa y de la que parte el moderno positivismo lógico y la teoría verificacionista del significado ${ }^{2}$.

1. T.S. KuHN, La Estructura de las Revoluciones Científicas, Madrid, Fondo de Cultura Económica 1987, Posdata, p. 280.

2. «Una teoría del conocimiento rebajada a metodología pierde de vista la constitución de los objetos de la experiencia posible, de igual modo una ciencia formal, separada de la reflexion transcendental, desconoce la génesis de las reglas de conexión entre los símbolos; ambas ignoran (...) las operaciones sintéticas del sujeto cognoscente. La posición positivista oculta la problemática de la constitución del mundo. El sentido del conocimiento mismo se convierte en irracional». J. HABERMAS, Conocimiento e interés, Madrid, Taurus 1986, p. 77. «El objetivo de mi investigación es la crítica del cientifismo; y entiendo por cientifismo la actitud según la cual una filosofía cientifica tiene que proceder intentione recta como la ciencia misma, es decir, que debe mantener su objeto ante si (...). A la crítica del cientifismo se le plantea, pues, la tarea de hacer consciente la reflexión (negada, pero de la que filosóficamente se está haciendo uso siempre ya) como tal, es decir, una dimensión del problema del conocimiento que se ha hecho irreconocible». J. HABERMAS, o.c., p. 299. El subrayado es mío. Son esas actitudes las que definen los planteamientos. Tales actitudes son más importantes si cabe en las Ciencias Sociales que se ocupan de una realidad dinámica, variable, y a la que se pertenece, realidad que no es posible objetivar completamente: se participa de la historia y la verdad que alcanzamos está condicionada por esa historia (el grado en que lo está es una cuestión muy debatida. Cfr. R. Aron, Introducción a la Filosofía de la Historia, Buenos Aires, Siglo Veinte, vol. II, sección IV, pp. 11-45). 
¿Por dónde comenzar a analizar el status, la influencia y la validez de esos razonamientos previos? Creo que la opción más razonable consiste en comenzar por algunos de los autores que han dado origen a las corrientes más importantes de las Ciencias Sociales, porque son estos autores los que impregnan el razonamiento y los criterios cotidianos. Al diseñar un modelo de sociedad y ejercer una crítica a nuestra sociedad real, se constituyen en un banco de pruebas óptimo para investigar el porqué de esas opciones previas, su influencia y los límites que ponen al razonamiento de los que las utilizan. El análisis de esta lógica interna del razonar humano, que se construye sobre opciones válidas pero no absolutamente demostrables, quedará así al descubierto y nos permitirá, en primer lugar, entender mejor por qué ciertos autores dicen lo que dicen y concluyen lo que concluyen, y, en segundo lugar, cómo el dogmatismo de ciertas posturas es totalmente inaceptable, porque dicha postura se basa en razonamientos que en último extremo se eligen... (razonablemente, claro está, pero por eso mismo relativos, dependientes de cómo se conciba el ser del hombre, su finalidad, sus motivos y sus necesidades, etc.).

Con esto no defendemos un relativismo puro y duro, sino que queremos evidenciar cómo la relación entre la realidad y los discursos teóricos no es tan matemática, científica e incuestionable como algunos quisieran..., con lo que obtendremos un argumento en favor de la pluralidad y la mesura en el juicio. Obviamente, las teorías están ancladas en la realidad, pero la configuración que a partir de la misma realizan no tiene un carácter necesario, y debemos conocer en qué medida los puntos centrales a partir de los cuales se analiza son tan 'centrales', cuáles son sus características y limitaciones. El análisis de ciertos autores puede contribuir a esclarecer el panorama de nuestros razonamientos.

Nos situamos, pues, en las Ciencias Sociales. Al analizar los métodos que se utilizan en las Ciencias Sociales, von Wright indica la importancia de las opciones fundamentales al analizar conceptos como el de causalidad, explicación e intención, conceptos que articulan nuestra concepción de la metodología científica, del valor del método, de la libertad y de la amplitud de la relación causa-efecto en la cultura y en la sociedad ${ }^{3}$. Ahora bien, si la metodología es influida por la forma en que se entiendan estos conceptos (que constituyen el armazón en el que se insertan los datos objetivos), mucho más influyen

3. «Pero también existe una confrontación de base, al margen de la posibilidad tanto de reconciliación como de refutación (incluso, en cierto modo, al margen de la verdad). Se funda en la elección de conceptos primitivos, básicos para la argumentación en su conjunto. Podría calificarse esta elección de «existencial». Consiste en la opción por un punto de vista no susceptible de ulterior fundamento». G.H. von WRIGHT, Explicación y Comprensión, Madrid, Alianza Editorial 1987, p. 55. 
las concepciones que, desarrolladas por autores posteriores, ahora mismo están a la base y en el fondo de las explicaciones sobre el significado de los datos. Los científicos sociales no sólo presentan la realidad, sino que la presentan de cierta manera (como los periodistas o nosotros mismos), explorando su significado desde su peculiar perspectiva ${ }^{4}$. Es diferente el sentido categorial de un enunciado empírico del «sentido resoluble discursivamente de la pretensión de validez que vinculamos implícitamente a cada enunciado afirmado. El sentido en el cual un enunciado puede ser verdadero o falso (...) se basa (...) en la posibilidad de fundamentación argumentativa de una pretensión de validez razonable» ${ }^{5}$.

Conforme más unilateral, más partidista o dogmática sea la perspectiva, más se niega la amplitud del significado de la realidad social en base a una intuición previa, que al absolutizarse se olvida de la realidad de la que fue, quizás, en su día un reflejo. Hasta qué punto una Ciencia Social concreta, o más bien una metodología aplicada por unos científicos sociales determinados, es unilateral no es objeto de nuestro estudio ${ }^{6}$. Sin embargo, sí pretendemos analizar algunas de las visiones de autores que han influido grandemente en el desarrollo de las Ciencias Sociales, y que configuran de hecho muchos de nuestros juicios cotidianos. Hablamos de autores de la talla de Freud o Habermas, lugar de cita común en nuestros días. Intentaremos analizar algunos de sus puntos de partida, para comprender de dónde brota su discurso, y cuál es la fuente desde la que aportan su visión de la realidad social.

Quizás estos conceptos previos, intuiciones fundamentales de su razonamiento, son los que explican en algunos casos su limitación, en otros su tendencia al dogmatismo, al pesimismo, o su visión de un desarrollo necesario de la realidad social, de su historia. Pienso que puede ser ilustrativo, en cuanto es, un ejercicio sobre los límites de cada forma de ver las cosas, que pueden complementarse y, sin embargo, que condicionan el alcance del pensamiento del autor. Pero no sólo es ilustrativo en la comprensión de la teoría habermasiana de la intercomunicación, sino que es ilustrativo en nuestra vida diaria, porque esos conceptos son utilizados, y desde ellos se habla en numerosos casos. Este análisis nos permitirá enfrentarnos con mayor lucidez al editorialista de un periódico o al reportero televisivo, al reparar más fácilmente en los conceptos que utiliza y en los que se basa, en la dinámica propia de los mismos y en las consecuencias de sus afirmaciones. En muchos trabajos actuales, tanto

4. Salustiano DEl CAMPo, Ed. Tratado de Sociología vol. I, Madrid, Taurus 1986, p. 11.

5. J. HABERMAS, o.c., p. 310.

6. Los reduccionismos de todo tipo han sido denunciados por numerosos autores a lo largo de los últimos decenios. Recordemos el rechazo contra el reduccionismo neopositivista y la crítica del criterio de verificación por autores como POPPER o HANSON. 
sobre Metodología de las Ciencias Sociales como sobre análisis realizados por los científicos sociales propiamente dichos, la presencia de estos 'prejuicios', o imágenes previas de la realidad, que conducen el discurso sobre el sentido de los datos, y que se convierten en 'prejuicios' si se absolutizan, es patente. Incluso en un artículo de prensa observamos una trama conceptual en la que se vierten los datos ${ }^{7}$, trama que, por supuesto, no es la única posible ni la más verdadera. Nuestra reflexión sobre ciertos autores nos ayudará a valorar de forma crítica los mensajes que nos llegan...

Al desarrollar este análisis, los principales conceptos filosóficos de los autores estudiados salen a la luz, dándonos cuenta, a la vez, de la importancia del significado que en gran medida otorgamos a los acontecimientos; la lucha de clases sociales, el impulso del inconsciente, etc, enmarcan nuestra comprensión de la realidad social. Por poner un ejemplo, el dogmatismo implícito en las visiones que otorgan una necesidad intrínseca al desarrollo de los fenó-

7. Un fenómeno curioso que expresa la distancia que imprimen los supuestos básicos en la interpretación de la realidad - no sólo de lo que ha sido, sino de lo que debe ser- ha sido la campaña electoral americana del 88, junto con la anterior del 84: la prensa en general (especialmente los comentaristas políticos del New York Time) desarrolló una virulenta campaña contra la candidatura republicana. ¿Razones? En principio se supone que los comentaristas políticos de la prensa reflejan e influyen en la opinión del cuerpo social; por lo tanto, la prensa debería reflejar unos criterios socialmente compartidos en un grado tan amplio como la unanimidad de los diversos medios en torno a la cuestión. Si no fuese así, podríamos decir que hablan desde el vacío social y para el vacío social... Los republicanos ganaron las elecciones... ¿Podríamos decir que los supuestos básicos desde los que partía el análisis de los comentaristas, y los respectivos juicios de valor, eran distintos de los utilizados por la mayoría del cuerpo de electores? La objetividad de los comentaristas, al menos en lo que respecta a su percepción de la opinión social (o del nivel mayoritario tle opinión), así como su influjo 'ideológico' en el cuerpo social en el que viven y del que viven, quedó en entredicho. Podríamos plantearnos un interrogante: ¿no estarían más guiados por sus presupuestos 'ideológicos' que por la percepción de los valores y criterios aceptados como válidos y eficaces por la mayoría de la población? Con esto no quiero decir que los criterios más votados sean los mejores, ni que el periodista sea un simple vocero de la realidad social... Pero, ¿no es llamativo el hecho de que el electorado vote una alternativa que es sistemáticamente desechada y criticada como pésima por un gran sector de la prensa escrita? ¿Cuáles con los esquemas desde los que tanto periodistas como votantes valoran la realidad y las candidaturas? Si un individuo mantiene convicciones liberales, cualquier análisis del marxismo será, en último término, crítico y negativo. Igualmente, un individuo que parte de unos esquemas antropológicos y políticos marxistas, rechazará como 'mala' e 'inhumana', toda propuesta basada en una concepción liberal de la sociedad, la rechazará como alienadora, aunque sus criterios para tal rechazo sean ideológicos, no demostrables científicamente, basados en una relativa coherencia argumentativa y en un concepto de hombre del que se puede disentir. Por lo tanto, el mismo carácter de la actividad humana otorgadora de sentido y proveedora de criterios nos remite a una realidad plural. Lo profundamente inhumano es el dogmatismo y la afirmación absoluta de una idea, afirmación que niega el valor a cualquier otro razonamiento que sea distinto. El ejemplo propuesto ilustra hasta qué punto es importante analizar los supuestos desde los que se habla, supuestos que aportan un sentido específico a los datos; y cómo esos supuestos condicionan y configuran nuestra percepción y análisis de la sociedad... 
menos socio-históricos ('necesidad' que a menudo da origen a concepciones dogmáticas), queda al descubierto al plantearnos los conceptos claves del autor, y al quedar explícita su teleología o su modo de explicar los datos. Por otra parte, las propuestas que estos autores realizan también vienen definidas por su orientación básica, y en estos conceptos vemos el tipo de realidad social que proponen, el tipo de sociedad que contemplan. Cada uno diseña un horizonte social, un planteamiento sobre la evolución, visión que a menudo está

- también presente en los análisis actuales llevados a cabo por científicos sociales, periodistas y personas de la calle.

He de precisar que aquí entiendo por 'concepto previo' tanto una intuición original del autor (como el concepto de lucha de clases, que, como intuición original - clave de interpretación y de percepción de la realidad socialpasa a formar el núcleo de la interpretación marxista, constituyéndose en marco teórico en el que se integran los datos y que orienta el análisis; o el concepto del sentimiento de culpabilidad como característica central de la cultura) que se desarrolla a lo largo de su obra, como la concepción que tenga de la dinámica que articula el desarrollo de la sociedad (mecanicista, dialéctica), como conceptos epistemológicos básicos (convencionalista, realista, etc.), que influyen en la concepción de la ciencia, la ética o la política. En definitiva, esas opciones previas, a priori, señaladas por von Wright en su obra «Explicación y comprensión»: los ejes que guían un discurso filosófico determinado. Naturalmente, estos conceptos previos, estas opciones fundamentales, se desarrollan y evolucionan a lo largo de la obra del autor; suelen responder a un aspecto importante de la realidad social. Partiendo de la exposición de algunos autores, analizaré en la conclusión algunos aspectos particularmente importantes que se derivan de la propia naturaleza del conocimiento humano, y de su actividad 'aportadora' de sentido, como la importancia de los marcos teóricos o el peligro de los prejuicios y del dogmatismo.

\section{El horizonte de nuestro análisis: Marx, Freud, Fromm y la Escuela de Frankfurt}

Nuestro objetivo es resaltar cómo el razonamiento se vertebra a través de una serie de conceptos básicos, que estructuran y delimitan (siempre de un modo flexible) los márgenes dentro de los cuales se desarrolla nuestro pensamiento. La metodología es completamente empírica, siguiendo las modernas técnicas de análisis hermenéutico: elegiremos cuatro importantes autores de las Ciencias Sociales (con influjo en todas las ramas del pensamiento), y en ellos investigaremos la existencia de tales conceptos, emprenderemos una sucinta labor de caracterización de los mismos y de análisis del horizonte que propone, de la realidad social que diseñan. A partir de este análisis abordare- 
mos las cuestiones de fondo que surgen al plantear la pregunta por los 'conceptos previos': la cuestión del significado (en qué medida es relativo y en que medida nosotros los creamos, revistiendo de significado, de relevancia, la realidad en que nos movemos), la cuestión del dogmatismo y de las ideologías (que queda al descubierto al investigar los supuestos en los que se basa su discurso), así como la necesidad de cultivar una postura crítica, que nos permita 'desmontar' la concepción de la sociedad, de la existencia, de la realización personal, que permanentemente nos envían los medios de comunicación social, los ensayos de cualquier materia y signo, etc., adoptando una visión personal y liberadora.

Este objetivo es amplio. Tenemos que ceñirnos a un ramillete de autores. ¿Cuáles? En esta investigación nos centraremos en Marx, Freud, Fromm y Horkheimer. ¿Por qué? En primer lugar, porque los cuatro enlazan unos con otros (Fromm critica a Freud y Marx, Horkheimer critica a Freud, Fromm y Marx, y los contrastes entre Freud y Marx, así como sus semejanzas, son obvios), lo que nos permite acceder con más facilidad a sus supuestos básicos. Los cuatro (hablar de Horkheimer es hablar de la Escuela de Frankfurt) desarrollan un análisis de la sociedad, con una propuesta implícita o explícita de futuro. Los cuatro destacan aspectos particularmente importantes de la vida del individuo y de las relaciones sociales. $Y$, al concluir con ellos, nos situamos en plena contemporaneidad: autores como Habermas se sitúan en la corriente forjada por ellos, si bien con planteamientos originales.

En segundo lugar, estos cuatro autores son un lugar común de cita, de referencia y de crítica. Es importante alcanzar el núcleo, o, al menos, alguno de los puntos fundamentales, de sus análisis de la sociedad, porque en base a esos conceptos ellos ęstructuran su investigación, y son esos conceptos los que diseñan en alguna medida sus conclusiones... Como se puede suponer, no estoy defendiendo un idealismo en el cual el todo es el concepto. Estas intuiciones generales, como la formulación de las relaciones sociales en términos de lucha de clases, son desarrollos teóricos, pero parten de una realidad social. Estos autores no son eminentemente especulativos, aunque reserven un gran espacio a la reflexión teórica. Por otra parte, como la Historia de la Ciencia nos enseña, la recogida de datos sin una teoría previa que los encuadre, seleccione y organice, carece de sentido y significado.

Quizás fuese mejor utilizar la expresión 'marcos teóricos' para señalar estos conceptos 'clave', estas tomas de postura que, aunque partan de la realidad, se articulan y llegan a estructurar los posteriores análisis sobre ésta. Hemos de tener en cuenta que el objetivo de este trabajo es eminentemente filosófico; es una pregunta filosófico-crítica la que nos hacemos: ¿Cuál es el fundamento de la metodología utilizada por esos autores en su análisis de la socie- 
dad? ¿Qué imponen y qué diseño nos dan esas opciones previas del futuro? ¿Cuál es la dinámica propia de esas opciones previas? ¿Llevan, o pueden llevar, implícito un componente dogmático o crítico?

Lo que nos planteamos es analizar el trasfondo de esos análisis sociales. Es una forma de objetivar el presunto cientifismo de algunas teorías cuando abordan el 'sentido' de los hechos y de la realidad, y es una forma de evitar absolutizaciones previas. Como es evidente, sólo he elegido algunos conceptos de este tipo en cada autor. Creemos que puede ser ilustrativo analizar en Marx la teleología implícita en su concepción de la lucha de clases sociales y en su concepto de trabajo, en torno a los cuales diseña lo que debería ser y lo que llegará a ser el hombre en el más allá comunista... Analizar la noción de carácter social en Fromm, y el optimismo que le criticarían más tarde antiguos colegas como Horkheimer y Adorno. Investigar el papel del sentimiento de culpabilidad en la relación del hombre con la sociedad, tal y como lo expresa Freud. Presentar la opción de los frankfurtianos por la 'no-identidad' (exceptuando la obra posterior de Marcuse), que les llevará a un pesimismo práctico... Nos planteamos este trabajo como una autorreflexión sobre los conceptos principales que estructuran el análisis de la realidad social en ciertos autores que están presentes en las corrientes actuales de las Ciencias Sociales. $Y$ hemos querido hacerlo desde una perspectiva estrictamente filosófica. En las páginas que siguen veremos la dificultad de conseguirlo.

\section{DeSARRollo}

\section{Una opción por un futuro prometedor}

\subsection{La dialéctica hegeliana en la teleología marxista}

Marx toma como punto de partida el análisis del trabajo humano y de la mercancía. A partir de este análisis ahonda en la estructura de la sociedad capitalista, y diseña el futuro 'socialista' en el cual se producirá la superación de las actuales contradicciones y la realización del hombre, por cuanto el producto de su trabajo ya no será algo ajeno a él mismo, sino que el hombre se reali-

zará en el trabajo, que es el rasgo constitutivo de la especie humana. En todo el análisis están presentes las influencias hegelianas. ¿Cuál es la dimensión del trabajo para Marx?

- «Precisamente porque la naturaleza circundante se constituye en naturaleza objetiva para nosotros, tan sólo gracias a la intervención de la naturaleza subjetiva del hombre, mediante los procesos del trabajo social, es por lo 
que el trabajo representa no sólo una categoría antropológicamente fundamentadora, sino también, y al mismo tiempo, una categoría gnoseológica» ${ }^{8}$.

-De aquí que «la investigación materialista de la historia apunta a categorías de la sociedad que determinan de igual manera el proceso real de la vida que las condiciones transcendentales de la constitución de los mundos de la vida» ${ }^{9}$.

Marx, al analizar las estructuras básicas del trabajo social, descubre la síntesis que produce el hombre con la naturaleza que le rodea objetivamente. Dado que la síntesis tiene lugar en un medio gobernado por el trabajo, el punto de referencia para la reconstrucción de las realizaciones sintéticas es la 'economía'. Y en el análisis de la economía Marx se encuentra con un elemento que centrará particularmente su atención: la mercancía. El intercambio entre los hombres se realiza bajo esta categoría: son mercancías nuestros productos, y en cuanto tales entran en la dinámica del mercado. En esta objetivación y extrañamiento del producto del trabajo encuentra Marx la causa de la 'no realización' del hombre, de su estado frustrado en la sociedad capitalista; en ese 'extrañamiento' descubre el carácter fetichista de la mercancía: en ella se proyectan las relaciones sociales, y reificamos el producto de nuestro trabajo alejándolo de nosotros; «la apropiación del objeto aparece hasta tal punto como enajenación, que, cuanto más objetos produce el trabajador, tanto menos puede poseer y tanto más le domina su producto, el capital» ${ }^{10}$.

Para Marx, el trabajador de la sociedad capitalista se caracteriza precisamente por ese 'extrañamiento': «Todas estas consecuencias se hallan encerradas en una característica del trabajador: que el producto de su trabajo sea para él un objeto ajeno (...). Su vida propia, que es lo que el trabajador pone en el objeto, deja entonces de pertenecer a él para pertenecer al objeto" ". De aquí que Marx afirme: «(...) si el producto del trabajo es la extrañación, la producción misma tiene que ser la extrañación activa, la extrañación de la actividad, la actividad de la extrañación» ${ }^{12}$. Con lo que la actividad propia del hombre, el trabajo, en la que se realiza, se convierte en el lugar de su alienación y desencanto: «De modo que el trabajo enajenado, arrebatándole al hombre el objeto de su producción, le priva de su vida de especie» ${ }^{13}$.

En el análisis de la mercancía, concepto central en la sociedad mercado, descubre Marx un carácter fetichista que oculta precisamente la causa de esta

8. J. Habermas, Conocimiento e interés, Madrid, Taurus 1982, pp. 35-36.

9. Idem, o.c., p. 38.

10. K. MARX, Manuscritos de 1844, Madrid, Alianza Editorial 1976, p. 350.

11. Idem, o.c., p. 350.

12. Idem, o.c., p. 351 .

13. Idem, o.c., p. 355 . 
'enajenación': las relaciones sociales: «lo misterioso de la forma mercantil consiste sencillamente, pues, en que la misma refleja ante los hombres el carácter social de su propio trabajo, como propiedades sociales naturales de dichas cosas, $y$, por ende, en que también refleja la relación social que media entre los objetos, existente al margen de los productores. Es por medio de este qui pro quo (tomar una cosa por otra) como los productos del trabajo se convierten en mercancías» ${ }^{14}$. Marx especifica aún más: «lo que aquí adopta, para los hombres, la forma fantasmagórica de una relación entre las cosas, es sólo la relación social determinada existente entre aquellos (...). A esto llamo el fetichismo que se adhiere a los productos del trabajo no bien se los produce como mercancías y que es inseparable de la producción mercantil» ${ }^{15}$. Oigamos la tesis central: «Este carácter fetichista (...) se origina (...) en la peculiar índole social del trabajo que produce mercancías» ${ }^{16}$.

El hombre es su trabajo. De aquí la importancia de analizar su frustración o sus posibilidades de realización desde ese trabajo. Este trabajo es un trabajo social. Marx habla en plural: «lo que son (los hombres) coincide, por consiguiente, con su producción, tanto con lo que producen como con el modo cómo producen. Lo que los individuos son depende, por tanto, de las condiciones materiales de su producción» ${ }^{17}$.

$\mathrm{Al}$ exponer la evolución de las fases de desarrollo de la división del trabajo, Marx analiza la división en clases resultantes, y nos topamos con la presencia de la dialéctica hegeliana, que da origen al título de este epígrafe (sin olvidar que el concepto de trabajo como 'síntesis' se basa también en las categorías hegelianas) ${ }^{18}$.

En la obra de Marx aparecen dos enfoques sobre el tema de las clases sociales: en un primer enfoque señala tres grandes clases que se diferencian funcionalmente en el sistema de producción capitalista, o realiza un análisis histórico detallado en el que aparecen varias clases concretas que actúan en ese período histórico; en un segundo momento, irá apareciendo una visión dual y antagónica de la estructura de clases. En «El manifiesto comunista» identificará el conflicto de clases como el conflicto entre dos grandes clases.

Al analizar esta interpretación de Marx, ¿qué nos encontramos?

— «La tesis de la reducción de la estructura de clases a una estructura dual

14. K. MARX, El Capital, Madrid, Siglo XX 1975, p. 88.

15. Idem, o.c., p. 89 .

16. Idem, o.c., p. 89.

17. K. MARX, La Ideología Alemana, Barcelona, Grijalbo 1974, pp. 19-20.

18. Marx nunca desarrolló una teoría general sobre las clases sociales. El capítulo 52 del libro tercero de «El Capital», con el título «Las clases» quedó inconcluso. Ahora bien, abordará fragmentariamente el tema en muchas de sus obras. 
antagónica es una tesis que, en esta formulación, va asociada (y reforzada) por otras tesis concretas reflejadas en 'El manifiesto' y también en otras obras marxistas. Estas tesis son, fundamentalmente, la tesis de la tendencia a la homogeneización y depauperación de la clase obrera, la tesis de la desaparición de las clases intermedias, y también la tesis, más general y difusa, que podemos enunciar como la tesis de la clase total» ${ }^{19}$.

- Marx va a tomar, como punto de referencia fundamental de lo que era una clase social, el modelo de la clase terrateniente inglesa. «A partir de estas coordenadas de referencia analítica, el ascenso de la burguesía industrial fue vista, en la perspectiva histórica, como el proceso de hegemonización de una nueva clase social total (...). Frente a este perfil social homogéneo y neto, resultaba evidente que de acuerdo a las necesidades de la lógica de las categorías del análisis hegeliano, no cabía más alternativa que prever su 'enfrentamiento' a otra clase social de características análogas y definidas a partir de una situación económica antitética a la burguesía. Así, en el análisis marxista, el proletariado es visto como la otra clase (...). De esta forma la idea de clase total, aplicada al análisis de un proceso histórico de dominación concreto, visto desde la óptica de las categorías hegelianas (...) conducía (...) a una necesaria reducción dual de la estructura de clases» ${ }^{20}$.

Como colofón de estas reflexiones resaltamos tres puntos:

1. «Desde una perspectiva histórica retrospectiva, parece claro que la visión de Marx sobre la clase obrera estaba pensada, más bien, en función tanto del papel histórico que debía cumplir (a partir de las coordenadas dialécticas hegelianas), como de la misma necesidad (a partir de éstas) de cubrir lo que podíamos calificar como el espacio social de la antítesis, a través de la que llegar a la síntesis final. Y esto determinaba, 'forzosamente', la adopción metodológica de un esquema dual de clases puras, decantadas de ambigüedades y contradicciones. Por ello, ya en el primer Marx nos encontramos claramente cómo el análisis social concreto aparece bastante teñido de un finalismo confesado" ${ }^{21}$.

2. «La inserción de esta argumentación, con evidentes matices finalistas, en la lógica de la situación del sistema de producción (vista desde la óptica hegeliana) se planteará en términos de subrayar que 'proletariado y riqueza' son términos antagónicos» ${ }^{22}$.

19. J.F. TeZanos, Principales teorías sobre la estratificación social, en «Tratado de Sociología» (comp.), vol. I, Madrid, Taurus 1986, p. 270.

20. Idem, o.c., p. 273.

21. Idem, o.c., pp. 273-274.

22. Idem, o.c., p. 275. 
3. «Vistas así las cosas, el siguiente paso del análisis consistió en demostrar, por una parte, cómo se iba a producir el incremento numérico del proletariado que conduciría a la afirmación de su hegemonía social (...) y, por otra, a explicar cómo este incremento numérico (hegemonía social) se traduciría en hegemonía política»" ${ }^{23}$. Desde esta perspectiva hay que entender 'El Capital': «En realidad, Marx, en 'El Capital', va a intentar demostrar científicamente, en las perspectivas del análisis de los economistas, muchas de las tesis que había mantenido anteriormente desde ópticas más cercanas a la filosofía hegeliana, o directamente vinculadas a la acción política» ${ }^{24}$.

En esta breve exposición, hemos planteado tanto la postura de Marx (a partir de sus escritos) como la crítica sobre los supuestos que le impulsan a una teleología que difícilmente puede calificarse de científica; más bien es un desiderátum. No entramos en el análisis de las limitaciones del concepto de producción y trabajo marxista, que, según Habermas, le impide una adecuada concepción de lo simbólico y de la crítica reflexiva propia del hombre, y que influye en la dinámica histórica. Pero sí creo que quedan claros los puntos de partida del análisis, que condicionan sus resultados y que, por lo tanto, sólo son válidos en cuanto propedéuticos, en cuanto descubren una cara de la realidad. Ahora bien, el impulso hegeliano y cientifista lleva a Marx a convertirse en 'intérprete' de toda la realidad social, (al menos para muchos de sus discípulos), intentando reducir ésta a sus esquemas teóricos, con lo cual se llega a extremismos y situaciones absurdas que todos conocemos. El dogmatismo implícito que se esconde en las posturas últimas y absolutas acecha, también, a la interpretación marxista. Este peligro se hace realidad cuando el análisis social se convierte en ideología (discurso con pretensiones de verdad absoluta y por lo tanto falso).

Es importante que destaquemos algunas limitaciones internas del 'horizonte' de realización personal del hombre que presenta el concepto marxista de producción, porque, al menos para mí, no está nada claro cómo resolver ese 'extrañamiento', y cómo conciliar la reasunción por el hombre de su trabajo y la división del trabajo, que debe existir necesariamente por la propia exigencia de la sociedad: «la dependencia total, forma natural de la cooperación histórico-universal de los individuos, se convierte, gracias a la revolución comunista, en el control y la dominación consciente sobre estos procesos» ${ }^{25}$. $\mathrm{Al}$ final, triunfará el proletariado. Y entonces, ¿qué? ¿La dinámica histórica seguirá igual, con su proceso dialéctico? ¿O el método, como en Hegel, cederá el

23. Idem, o.c., p. 276.

24. Idem, o.c., p. 277.

25. K. MARX, La Ideología Alemana, Barcelona, Grijalbo 1979, p. 39. 
paso al sistema, y se dará por concluida la historia? Más aún, esa conciencia colectiva que reasume su trabajo (aunque la dependencia recíproca y por lo tanto la división del trabajo continúe), esa satisfacción de recuperar 'la propia producción', ¿no es tan idealista como las tesis hegelianas? Ese sentimiento del hombre universal es una abstracción tal que la rebelión de la población alemana por café y azúcar (que Marx analiza en 'La Ideología Alemana') constituye su propia fosa. Para mí, en último término la conciencia de clase es una abstracción, en la que el hombre concreto se proyecta y que es válida en cuanto mejora a través de la lucha su situación. No fundamenta la propia conducta sino en cuanto el individuo hace un esfuerzo de abstracción para que la solidaridad intelectual le 'satisfaga', y le dé un motivo para la honradez, para la generosidad, la alegría y la tenacidad. Es casi una satisfacción 'mística' de la conciencia que se autoasume y que..., dados los presupuestos marxistas sobre lo material y la producción, es difícilmente realizable: al final, el hombre lucha por ese café y por el azúcar. Esto no quiere decir que no tenga capacidad de sacrificio por un ideal, ni que no intente mejorar, sino que indica el camino de la auténtica mejora: mayor bienestar material, más cultura, más posibilidades de elegir un rumbo personal y realizante en la vida, etc. Es muy discutible el avance del 'socialismo real' en estos y otros sectores. El problema es si la propuesta de Marx constituye, desde sus puntos de partida (al margen del acierto de sus análisis puntuales), un marco de realización 'posible' para el hombre concreto, tal y como es, con su capacidad para lo simbólico y para el trabajo. Más adelante, cuando nos enfrentemos con la Escuela de Frankfurt, expondremos las críticas de ésta a Marx, y sobre todo la lucidez que manifiestan al analizar un componente que Marx no tuvo en cuenta al proponer la victoria del proletariado: el peligro del dogmatismo y de la absolutización del Partido.

A pesar de las críticas, no podemos olvidar el fondo positivo del pensamiento de Marx, el reto fundamental que nos lanza: «(...) Marx sólo podrá estar realmente superado cuando históricamente todos los miembros de las sociedades humanas hayan alcanzado materialmente la posibilidad de decidir colectiva y racionalmente acerca de la organización de sus recursos y de su forma de vida» ${ }^{26-27}$. El problema es 'plasmarlo'. Si el hombre se mide por sus 'realizaciones históricas' (criterio de enjuiciamiento aportado por el propio Marx), la plasmación histórica concreta del socialismo 'real', suscita muchos interrogantes.

26-27. JiméneZ, Filosofia y emancipación, Madrid, Espasa-Calpe 1984, p. 29. 


\subsection{Fromm: voluntad positiva para humanizar}

Abordamos a Fromm en este punto porque, junto a la voluntad positiva para desarrollar la personalidad del individuo, y junto al diseño de ese horizonte posible de libertad personal, observamos la ausencia de esa teleología cientifista presente en Marx: el progreso ya no es algo que advendrá necesariamente. Puede que el fracaso tome cuerpo y el hombre no avance hacia su realización. Fromm aborda el estudio de la sociedad no desde un supuesto previo, sino desde su realidad profunda; el carácter social y la estructura psicosocial del hombre. Al desarrollar su investigación, Fromm dibuja también un futuro posible, y expresa la capacidad del hombre para alcanzarlo, capacidad alimentada por la propia constitución y necesidades del hombre.

El punto de partida en el análisis de Fromm es el carácter social: éste comprende una selección de los rasgos que configuran la personalidad del individuo, a saber: «el núcleo esencial de la estructura del carácter de la mayoría de los miembros de un grupo; núcleo desarrollado como resultado de las experiencias básicas y los modos de vida comunes del grupo mismo» ${ }^{28-29}$. Por eso nos centraremos específicamente en esta noción, que proyecta una determinada imagen del hombre y de sus posibilidades. Fromm precisa:

-El carácter es la «forma específica impresa a la energía humana por la adaptación dinámica de las necesidades de los hombres a los modos de existencia peculiares de una sociedad determinada $\gg{ }^{30}$.

-Determina «el pensamiento, la acción y la vida emocional de los individuos» ${ }^{31}$. La estructura concreta del carácter social nos proporciona una clave para entender tanto las ideas como las actuaciones de una sociedad determinada: la comprensión de las ideas y actos no se limita a una variable económica o ideológica: «El hecho de que las ideas se desarrollen en una matriz emocional, posee la mayor importancia, por cuanto constituye la clave necesaria para lograr la comprensión del espíritu de una cultura»" ${ }^{32}$. Precisamente esa 'matriz emocional' nos indica su campo de actuación: «las ideas pueden llegar a ser fuerzas poderosas, pero sólo en la medida en que satisfagan las necesidades humanas específicas que se destacan en un carácter social dado" ${ }^{33}$. Fromm remite al hombre concreto, no especula, y remite a la sociedad concreta, con sus impulsos soterrados, no a una estructura independiente y a-humana.

Esa matriz emocional, ese carácter, determina tanto las ideas como las

28-29. E. Fromm, El miedo a la libertad, Buenos Aires, Paidos 1966, pp. 322-323.

30. Idem, o.c., p. 323.

31. Idem, o.c., p. 323.

32. Idem, o.c., p. 325.

33. Idem, o.c., p. 327. 
acciones. Es iluso pensar que nuestra razón es algo aparte de nuestra situación y características concretas: «el llamado comportamiento racional está determinado en gran parte por la estructura del carácter» ${ }^{34}$. Dada la estructura humana, el carácter desempeña una función específica tanto respecto al individuo como respecto a la sociedad:

- «La función subjetiva del carácter para una persona normal es la de conducirlo a obrar de conformidad con lo que le es necesario desde un punto de vista práctico y también a experimentar una satisfacción psicológica derivada de esa actividad» ${ }^{35}$.

- «Si consideramos el carácter social desde el punto de vista de su función en el proceso social, deberemos partir del principio que se ha formulado con referencia a su función subjetiva; al adaptarse a las condiciones sociales el hombre desarrolla aquellos rasgos que le hacen experimentar el deseo de obrar justamente de ese modo en que desea hacerlo» ${ }^{36}$.

Para el desenvolvimiento de la actividad cotidiana, es fundamental esa actuación del carácter social, que «internaliza las necesidades externas, enfocando de este modo la energía humana hacia tareas requeridas por un sistema económico y social determinado" ${ }^{37}$. Fromm no olvida que la 'gratificación' psicológica y física es fundamental para mantener un esfuerzo y para luchar por una meta. Precisamente el entusiasmo y la entrega sólo se pueden asegurar mediante la realización psicológica del individuo. Por eso ciertas utopías son totalmente irrealizables.

Esa tensión interna, psico-social, es la que conduce al hombre bien hacia la libertad, bien hacia el fanatismo. Fromm interpreta la dinámica social desde esta perspectiva:

- (...) una vez que en una estructura de carácter se han originado ciertas necesidades, toda conducta conforme con aquéllas resulta al mismo tiempo psicológicamente satisfactoria y de utilidad práctica desde el punto de vista del éxito material. Mientras una sociedad siga ofreciendo simultáneamente esas dos satisfacciones, se da una situación en la que las fuerzas psicológicas están cimentando la estructura social» ${ }^{38}$.

-Las crisis suceden porque «antes o después, sin embargo, se produce un retraso» ${ }^{39}$. Al no lograr las necesidades psicológicas ser satisfechas de la forma habitual, se proyectan en otros cauces, transformándose en dinamita

34. Idem, o.c., p. 327.

35. Idem, o.c., p. 329.

36. Idem, o.c., p. 329.

37. Idem, o.c., p. 330 .

38. Idem, o.c., p. 330

39. Idem, o.c., p. 330. 
preparada para destruir el orden existente. De aquí que ciertas actitudes antidemocráticas deban contemplarse desde esta dimensión psicológico-histórica, así como desde aquí debe analizarse el auge de ciertas ideologías.

Ya hemos analizado brevemente el concepto de carácter social, su constitución y características, su influencia en las ideas y en las actuaciones, y las funciones que desempeña en relación con el individuo y en relación con la sociedad, así como su papel en la dinámica social. Nos enfrentamos con una dimensión previa y constituyente del 'homo faber' de Marx. ¿Cómo se relaciona el hombre concreto con ese carácter? Fromm precisa los límites: «Si bien es cierto que las necesidades de la estructura económica y social de la comunidad moldean al hombre, su capacidad de adaptación no es infinita» ${ }^{40}$.

A la hora de plantearnos una actuación social, a la hora de formular un proyecto de sociedad, de convivencia, a la hora de diseñar una utopía que nos saque en algún grado de la miseria presente, debemos recordar que «hay ciertas cualidades psicológicas inherentes al hombre que deben necesariamente ser satisfechas y que originan determinadas reacciones si se ven frustradas» ${ }^{41}$. No basta con hablar del espíritu autoconsciente o de la reintegración del trabajo en el sujeto productor. Ni basta con afirmar la existencia de un futuro paraíso, en el más allá dentro del tiempo o en el más allá eterno. Fromm se detiene en el hombre concreto, porque es en su vida concreta donde se resuelve su felicidad, su realización, su trabajo, y desde la que surgen respuestas e instintos mal formulados al frustrarse su camino inicial. Fromm señala estas cualidades:

- «La más importante es la tendencia a ensanchar y a realizar las potencialidades que el hombre ha desarrollado en el curso de la historia, tal, por ejemplo, el pensamiento creador y artístico, la facultad de tener experiencias emocionales y sensibles diferenciadas» ${ }^{42}$. Estas cualidades son potencialidades del hombre que poseen un dinamismo propio, y según se desarrollan en el proceso evolutivo tienden a ser expresadas. Al analizar esta tendencia general hacia el crecimiento, precisa dos aspectos:

1. La represión de esta tendencia origina nuevas reacciones, especialmente con la formación de impulsos simbióticos y destructivos.

2. «(...) esta tendencia general al crecimiento (...) origina impulsos específicos, como el deseo de libertad y el odio a la opresión, dado que la libertad constituye la condición fundamental de todo crecimiento» ${ }^{43}$. Precisamente

40. Idem, o.c., p. 333.

41. Idem, o.c., p. 334.

42. Idem, o.c., p. 334.

43. Idem, o.c., p. 334. 
debemos comprender la realidad individual y social desde el punto de vista del crecimiento o represión de estas potencialidades, que permanecen a pesar de ser negadas, y cuya negación genera un odio consciente o inconsciente.

- «La tendencia a la justicia y a la verdad constituye un impulso inherente a la naturaleza humana, aun cuando puede ser reprimido y pervertido, como el de la libertad» ${ }^{44}$. Fromm precisa al exponer estas tendencias, y por lo tanto los límites que las mismas ponen a la estructura social, que la «única vía que (...) puede seguirse para explicar esas tendencias hacia la justicia y la verdad, es la de analizar toda la historia social e individual del hombre ${ }^{45}$. Este es el lugar en el que encontraremos el fundamento y el origen, lejos de hipótesis filosóficas o religiosas. Y en el análisis de la historia social e individual del hombre llegamos a las siguientes conclusiones:

1. «(...) para quien carece de poder, la justicia y la verdad constituyen las armas más importantes en la lucha dirigida a lograr la libertad y asegurar la expansión» ${ }^{46}$. Así, el individuo atraviesa en la niñez un período de impotencia, en el que se desarrollan rasgos como el sentido de la justicia y la verdad, rasgos capaces de constituir potencialidades comunes a toda la humanidad como tal.

2. Este carácter de la naturaleza humana expresa el siguiente hecho: «si bien el desarrollo del carácter es estructurado por las condiciones básicas de la vida, y si bien no existe una naturaleza humana fija, ésta posee un dinamismo propio que constituye un factor activo en la evolución del proceso social» ${ }^{47}$.

3. De aquí que «los derechos inalienables del hombre a la libertad y a la felicidad se fundan en cualidades inherentemente humanas: su tendencia a vivir, a ensancharse, a expresar las potencialidades que se han desarrollado en él durante el proceso de la evolución histórica» ${ }^{48 .}$

Así pues, vamos a concluir este acercamiento a Fromm resaltando que sus concepciones sobre el carácter social y sobre esas potencialidades humanas generadas en el transcurso de la historia, de la evolución histórica, le dan pie para desarrollar una comprensión de los hechos y de los movimientos sociales e ideológicos notablemente distintos de los marxistas y de otros que estudiamos en este trabajo. Esa concepción de la naturaleza humana que, según él, se verifica en el análisis socio-histórico, dibuja un marco diferente para la acción social. Ya no hay una necesidad lógica férrea en la historia, ni advendrá un

\footnotetext{
44. Idem, o.c., p. 334 .

45. Idem, o.c., p. 335.

46. Idem, o.c., p. 335.

47. Idem, o.c., p. 335.

48. Idem, o.c., pp. 335-336.
} 
paraíso futuro, sino que los impulsos del hombre pueden ser frustrados, y el hombre encaminarse hacia el miedo y la negación de la libertad. Pero, en esa negación hay un precio que pagar: la insatisfacción y el odio. Fromm apuesta por una lucha de humanización que recoge lo más puro del hombre, pero que es consciente de que no hay un rumbo teledirigido en la historia: el voluntarismo de Fromm, en cuanto deseo y en cuanto medio de realización de las potencialidades humanas, es consciente del fracaso, aunque apuesta por ese desarrollo y por ese final liberador: su teleología, su propuesta en torno a un fin, un fin que se alimenta de la propia evolución histórica del hombre y de las potencialidades por ella provocadas, no es mecanicista ni necesaria. Hay que luchar por ella; es una postura de fe en lo mejor del hombre, y el horizonte de realización que nos presenta es profundamente humano, inteligible, comprensible. Tales características se reflejan en su análisis del amor: «Tener fe en la posibilidad del amor como fenómeno social y no sólo excepcional e individual, es tener una fe racional basada en la comprensión de la naturaleza misma del hombre» ${ }^{49}$.

Hay dos aspectos de la crítica realizada sobre la obra de Fromm que nos interesan especialmente:

1. Crítica a su 'naturalismo' implícito:

«En vez de realzar la cualidad no representativa de la verdad y la imposibilidad de definir el hombre esencial, Fromm afirmó la noción de una antropología filosófica. (...) entendió la naturaleza del hombre como algo creado a través de la vinculación con el mundo y la interacción con los otros (...) se trataba (...) de una idea de la naturaleza potencial del hombre, similar a la physis griega (...). Al intentar fundar su visión de un hombre perfeccionado en la naturaleza esencial del hombre, Fromm buscó vislumbres de esa naturaleza en la obra de pensadores como Spinoza y Dewey. Y en la década de 1940 intentó ir más allá de la psicología, hacia un sistema ético basado también en la naturaleza humana. Tras la apariencia humanista de su ética, que alcanzaría su más completa expresión en Man for Himself (1947), acechaba allí un naturalismo que algunos críticos hallaron difícil de defender» ${ }^{50}$. A. Caparrós plantea los límites del razonamiento de Fromm en este apartado: «aun suponiendo, como supone Fromm, que esa naturaleza humana fuera una entidad con dinámica propia, y que su conocimiento fuera posible, este conocimiento sólo nos diría cómo es la naturaleza humana, sin que jamás pudiéramos deducir directamente cómo debería ser o qué valores la harían buena. Desde otra perspectiva, di-

49. E. Fromm, El arte de amar, Barcelona, Paidos 1987, p. 128.

50. Martin JAY, La imaginación dialéctica, Madrid, Taurus 1986, pp. 155-156. 
ríamos que el conocimiento de la naturaleza humana pertenece al ámbito de la ciencia teórica, mientras que el conocimiento ético como tal es propio de la razón práctica. Esto significa que el hombre no puede llegar a conocer los valores más que por mediación de la praxis de la libertad, praxis que sólo es posible en la historia, en la sociedad y en la cultura. Por mucho que Fromm se esfuerce, jamás nos convencerá de la posibilidad lógica de pasar directamente y sin mediación alguna del conocimiento de la naturaleza humana al conocimiento de los valores que hacen de dicha naturaleza una naturaleza humana «buena» ${ }^{51}$.

2. El optimismo histórico:

«Lo nuevo en Escape from Freedom, sin embargo, era un interés más general en lo que podía llamarse la condición 'existencial' del hombre (...). La noción de alienación, que Fromm había encontrado tan sugestiva en los primeros escritos de Marx, estaba claramente en la raíz de su nuevo enfoque. Ahora los dos polos de su pensamiento eran aislamiento y vinculación (...). En Escape from Freedom, distinguía entre la atomización aislada de una 'libertad desde' negativa y la 'actividad espontánea de la personalidad integrada, total', de la 'libertad hacia' positiva. Aunque se esforzara en mencionar el cambio socioeconómico que resultaría necesario para terminar la alienación de la «libertad desde» y lograr una «libertad hacia» positiva, no ponía matu énfasis sobre las dificultades de esta transformación. Llegó a ver el problema del cambio en términos cada vez más optimistas, incluso moralistas (...). En sus escritos posteriores Fromm subrayaría la integración de ética y psicología» ${ }^{52}$.

Adorno y Horkheimer se distanciaron de Fromm, acusándole de un optimismo ingenuo, que se revelaba en última instancia conformista. Para Horkhejmer, Fromm y Horney retornan a la psicología vulgar e «incluso psicologizan la cultura y la sociedad» ${ }^{53}$. Horkheimer se resiste a subordinar la psicología a la sociología en función de su énfasis en la 'no-identidad', como veremos más adelante. Para Adorno, «las implicaciones de la obra de los revisionistas, a pesar de sus negativas, eran, en última instancia, conformistas; esto se revelaba especialmente en su creciente moralismo $>{ }^{54}$. La distancia entre Fromm y sus antiguos colegas del Institut se acrecentó en la medida en que éstos intensificaron su valoración de la obra de Freud (causa de su creciente pesimismo), y

51. A. CAPARRós, El carácter social según Erich Fromm, Salamanca, Sígueme 1975, p. 200. Para una mayor información sobre este tema, cfr. John ScHAER, Escape from Authority: The Perspectives of Erich Fromm, New York 1961, pp. 20-24.

52. MARTIN JAY, La imaginación dialéctica, o.c., pp. 172-173.

53. Idem, o.c., p. 177.

54. Idem, o.c., pp. 157-158. 
en la medida en que Fromm se alejó de la obra de Freud; "Aunque Fromm nunca cesó completamente en sus esfuerzos para fusionar psicoanálisis y marxismo, sus últimos intentos se apoyaron menos sobre aspectos determinados de la obra de Freud y cada vez más en enfoques psicológicos anticipados por el propio Marx (...). La noción profética de paz universal que había aprendido en su juventud lo llevó a considerar la nota similar pulsada por Marx y a alejarse de las implicaciones menos afirmativas del pensamiento de Freud» ${ }^{54}$. Frente a estas acusaciones, Fromm indicó que «la capacidad del hombre para la libertad, para el amor, etc., depende casi totalmente de las condiciones socioeconómicas dadas, y que sólo excepcionalmente puede hallarse, como señalé en The Art of Loving, que haya amor en una sociedad cuyo principio es el exactamente opuesto» ${ }^{55}$.

\section{El elemento negativo en el análisis de la sociedad}

\subsection{Freud: la reducción al impulso}

Al plantearnos analizar la contribución de Freud a la comprensión de la sociedad, y por lo tanto plantearnos cuál es el punto de partida y los presupuestos en los que se enmarca el análisis freudiano, nos encontramos con la amplitud de la obra de este autor, así como con la dificultad de exponer, brevemente, sus teorías sobre el individuo, a partir de las cuales extrapola sus teorías sobre la cultura ${ }^{56}$.

Sin embargo, la presencia del 'horizonte' freudiano, de sus claves de análisis e interpretación, y por lo tanto de su visión de la cultura, del hombre individual y del progreso, está presente en los análisis actuales de las Ciencias Sociales... Es un autor al que hay que acudir para comprender muchos razonamientos e implicaciones de muchos teóricos de la sociedad de nuestra época. Recordemos a Marcuse, y al propio Fromm, cuya relación con Freud hemos indicado brevemente.

Vamos, pues, a elegir un concepto, el de 'cultura', y vamos a estudiar la dinámica fundamental de la realidad cultural: la relación instintos-sentimiento de culpabilidad, y el futuro que nos ofrece esta comprensión de las cosas.

Al hablar de cultura, Freud habla también del antagonista de la cultura, el instinto agresivo del individuo: «la cultura domina la peligrosa inclinación agresiva del individuo, debilitando a éste, desarmándolo y haciéndolo vigilar por una instancia alojada en su interior» ${ }^{57}$. La agresión propia del individuo

55. Idem, o.c., p. 174.

56. J. HABERMAS, o.c., pp. 215-244.

57. S. FREUD, Obras completas, El malestar en la cultura, p. 3.053. 
es dirigida contra el propio yo, «incorporándose a una parte de éste, que en calidad de super-yo se opone a la parte restante, y asumiendo la función de la 'conciencia' (moral), despliega frente al yo la misma dura agresividad que el yo, de buen grado, habría satisfecho en individuos extraños» ${ }^{58}$.

Así pues, el movimiento básico de la cultura es eludir la violencia del individuo proyectándola hacia el individuo mismo. Precisamente en el estudio de la conciencia moral aborda Freud los rasgos y las fases de esta agresión introyectada, causa del sentimiento de culpabilidad que caracteriza al hombre y a la cultura moderna: «la tensión creada entre el severo super-yo y el yo subordinado al mismo la calificamos de sentimiento de culpabilidad» ${ }^{59}$.

Al analizar la conciencia moral, Freud señala dos fases:

-Angustia social: dado que a veces lo nocivo es lo que el yo desea, Freud afirma que es una influencia externa la que establece lo que debe considerarse bueno o malo. El motivo de esta subordinación a los demás es el desamparo y la dependencia en la que se halla el individuo respecto de sus semejantes. «Así, pues, lo malo es, originalmente, aquello por lo cual uno es amenazado con la pérdida del amor» ${ }^{60}$. De aquí que en esta fase el sentimiento de culpabilidad sea sólo 'angustia social'. Tal angustia se caracteriza por el hecho de que su temor sólo es relativo a la posibilidad de ser descubierto.

- La conciencia moral y el sentimiento de culpabilidad propiamente dicho surgen cuando la autoridad es internalizada al establecerse un super-yo. «Con ello, los fenómenos de la conciencia son elevados a un nuevo nivel, y en puridad sólo entonces se tiene derecho a hablar de conciencia moral y de sentimiento de culpabilidad» ${ }^{61}$. Esta fase tiene características específicas:

1. «(...) Nada puede ocultarse ante el super-yo» ${ }^{62}$. Freud es tajante: «El super-yo tortura al pecaminoso yo con las mismas sensaciones de angustia y está al acecho de oportunidades para hacerlo castigar por el mundo exterior» ${ }^{63}$. Deja de actuar el temor a ser descubierto.

2. «(...) la conciencia moral (...) se comporta tanto más severa y desconfiadamente cuanto más virtuoso es el hombre» ${ }^{64}$. El yo se esfuerza en vano por ganar la confianza de su mentor, y vive siempre insatisfecho.

3. La adversidad, la frustración exterior, «intensifica enormemente el poderío de la conciencia en el super-yo» ${ }^{65}$. Ante el fracaso las exigencias de la

58. Idem, o.c., p. 3.053

59. Idem, o.c., p. 3.053 .

60. Idem, o.c., p. 3.054 .

61. Idem, o.c., p. 3.054 .

62. Idem, o.c., p. 3.054 .

63. Idem, o.c., p. 3.055 .

64. Idem, o.c., p. 3.055 .

65. Idem, o.c., p. 3.055 . 
conciencia moral se elevan, pensamos que no somos amados y nos sometemos a las exigencias del super-yo.

Así pues, al analizar la dinámica de la cultura nos hemos encontrado con un conflicto entre el individuo agresivo y la colectividad, y por lo tanto con la expresión de ese conflicto, que es el sentimiento de culpabilidad. De este sentimiento (que, según Freud, caracteriza nuestra cultura) nos vamos a ocupar en adelante:

-Según Freud, conocemos dos orígenes del sentimiento de culpabilidad: «uno es el miedo a la autoridad; el segundo, más reciente, es el temor al superyo. El primero obliga a renunciar a la satisfacción de los instintos; el segundo impulsa, además, al castigo» ${ }^{66}$. Originalmente, la renuncia instintual es una consecuencia del temor a la autoridad exterior, pero con la renuncia viene la tranquilidad. Sin embargo, «no sucede lo mismo con el miedo al super-yo. Aquí no basta la renuncia a la satisfacción de los instintos, pues el deseo correspondiente persiste y no puede ser ocultado ante el super-yo» ${ }^{67}$. En consecuencia, siempre surgirá el sentimiento de culpabilidad: «el individuo ha trocado una catástrofe exterior amenazante (...) por una desgracia interior permanente: la tensión del sentimiento de culpabilidad» ${ }^{68}$. Precisamente en el super-yo reside la indestructibilidad de este sentimiento, y precisamente la permanencia del mismo condena al hombre a un continuo afán, a un continuo pedir perdón que nunca alcanza el final feliz. El individuo siempre vivirá su relación social desde esta perspectiva.

-Freud describe así la secuencia cronológica: «ante todo se produce una renuncia instintual por temor a la agresión de la autoridad exterior (...) luego se instaura la autoridad interior (...) por el miedo a la conciencia moral. En el segundo caso se equipara la mala acción con la intención malévola, de modo que aparece el sentimiento de culpabilidad y la necesidad de castigo. La agresión por la conciencia moral perpetúa así la agresión por la autoridad» ${ }^{69}$. Observamos, pues, que el individuo vive bajo ese conflicto internalizado, y que define tanto a nivel individual como social la realidad cultural. Al precisar más las causas de la formación del super-yo y de la conciencia moral, Freud señala que a esta formación concurren tanto factores constitucionales innatos como influencias del medio ambiente, dualidad que representa «la condición etiológica general de todos estos procesos» ${ }^{70}$. La divergencia de ambos puntos de vista se atenúa si se pasa de la historia evolutiva a la historia filogenéti-

66. Idem, o.c., p. 3.056 .
$67 . \quad$ Idem, o.c., p. 3.056 .
68. Idem, o.c., p. 3.056 .
69. Idem, o.c., p. 3.055 .
70. Idem, o.c., p. 3.058. 
ca. Al analizar esta historia filogenética, Freud explica, a través de la primitiva ambivalencia frente al padre, tanto la participación del amor en la génesis. de la conciencia como el carácter fatalmente inevitable del sentimiento de culpabilidad: «Efectivamente, no es decisivo si matamos al padre o si nos abstuvimos de hacerlo: en ambos casos nos sentiremos por fuerza culpables, dado que este sentimiento de culpabilidad es la expresión del conflicto de ambivalencia, de la eterna lucha entre el Eros y el instinto de destrucción o muerte» ${ }^{71}$.

-Freud afirma que «este conflicto se exacerba en cuanto al hombre se el impone la tarea de vivir en comunidad» ${ }^{72}$. Freud es categórico: «El proceso que comenzó en relación con el padre concluye en relación con la masa. Si la cultura es la vía ineludible que lleva de la familia a la humanidad, entonces, «a causa del innato conflicto de ambivalencia, (...), la cultura está ligada indisolublemente con una exaltación del sentimiento de culpabilidad, que quizá llegue a alcanzar un grado difícilmente soportable para el individuo»" ${ }^{73}$. El latente conflicto del individuo no se resuelve, sino que se proyecta en la sociedad, en la cultura, y al independizarse del propio individuo se convierte en un sentimiento de culpabilidad colectivo, en un combate entre los instintos agresivos y el control para la supervivencia de la especie que ejerce la cultura, y que oprime al individuo. La cultura se configura como un medio de asegurar la supervivencia, pero al precio de controlar y cortar los instintos agresivos del hombre, y muchos de sus deseos inconscientes, y por lo tanto condenándolo a un continuo ejercicio de persecución y castigo sobre sí mismo.

$\mathrm{Al}$ detenernós en el análisis del sentimiento de culpabilidad, nos guiaron las palabras de Freud, que intenta destacar «el sentimiento de culpabilidad como problema más importante de la evolución cultural, señalando que el precio pagado por el progreso de la cultura reside en la pérdida de felicidad por el aumento del sentimiento de culpabilidad» ${ }^{74}$. Este sentimiento de culpabilidad engendrado por la cultura no se percibe fácilmente en cuanto tal, sino que puede permanecer inconsciente en gran parte o puede expresar un malestar que se trata de atribuir a otras motivaciones. Más aún, el origen de la cultura se sitúa en el origen del sentimiento de culpabilidad.

El sentimiento de culpabilidad es producto directo del conflicto entre «la necesidad de amor parental y la tendencia a la satisfación instintual, cuya inhibición engendra la agresividad» ${ }^{75}$. Al analizar el papel de la agresividad,

$\begin{array}{ll}\text { 71. } & \text { Idem, o.c., p. } 3.059 . \\ \text { 72. } & \text { Idem, o.c., p. } 3.059 . \\ \text { 73. } & \text { Idem, o.c., p. } 3.059 . \\ \text { 74. } & \text { Idem, o.c., p. } 3.060 \text {. } \\ \text { 75. } & \text { Idem, o.c., p. } 3.062 .\end{array}$ 
Freud se percata de que, al surgir el super-yo, la diferencia entre la agresión intencionada y la realizada perdió toda importancia por la omnisapiencia del super-yo. Y en ambos casos la agresión es desplazada hacia dentro: de ahí que la fuerza de la agresión pertenezca siempre al individuo, que ejerce violencia sobre sí mismo en la forma de angustia y de castigo. Por lo tanto, en el origen del sentimiento de culpabilidad descubierta por el psicoanálisis» ${ }^{76}$. La dinámica es la siguiente: «cuando un impulso instintual sufre la represión, sus elementos libidinales se convierten en síntomas, y sus componentes agresivos, en sentimiento de culpabilidad» ${ }^{77}$.

Freud caracteriza la cultura y el individuo dentro de un mismo proceso, la lucha entre Eros y el instinto de muerte:

- «(...) tanto el proceso cultural de la humanidad como el de la evolución individual no son sino mecanismos vitales, de modo que han de participar del carácter más general de la vida» ${ }^{78}$. Podemos observar que el desarrollo individual y el desarrollo de la cultura son de índole muy semejante.

-Freud señala un rasgo diferencial enormemente importante entre ambos procesos:

1. «La evolución del individuo sustenta como fin principal el programa del principio del placer, es decir, la prosecución de la felicidad» ${ }^{79}$.

2. «(...) El proceso cultural es aquella modificación del proceso vital que surge bajo la influencia de una tarea planteada por el Eros y vigilada por Ananké, por la necesidad exterior real: tarea que consiste en la unificación de individuos aislados para formar una comunidad libidinalmente vinculada» ${ }^{80}$. Freud afirma que «la inclusión en una comunidad humana o la adaptación a la misma aparece como un requisito casi inedulible que ha de ser cumplido para alcanzar el objetivo de la felicidad» ${ }^{81}$. De forma opuesta a la evolución individual, en la que prima el interés egoísta, en el proceso de la cultura el objetivo de establecer una unidad formada por hombres desplaza a un segundo plano la felicidad individual. De aquí que ambos procesos evolutivos puedan tener rasgos distintos, y que así como en cada individuo combaten dos tendencias antagónicas (la de la felicidad individual y la de la felicidad humana), así también se enfrentan los procesos evolutivos del individuo y de la cultura. Esta lucha no es, según Freud, hija de los protoinstintos (Eros y Muerte), sino

76. Idem, o.c., p. 3.063

77. Idem, o.c., p. 3.063 .

78. Idem, o.c., p. 3.063 .

79. Idem, o.c., p. 3.064 .

80. Idem, o.c., p. 3.064

81. Idem, o.c., p. 3.064 . 
que «responde a un conflicto en la propia economía de la líbido, conflicto comparable a la disputa por el reparto de la líbido entre el yo y las objetos» ${ }^{82}$. La esperanza reside en que si el individuo puede llegar a un equilibrio, también puede llegar ese equilibrio a la cultura. Es importante señalar este brote de esperanza que Freud aporta a su teoría del sentimiento de culpabilidad.

Por analogía con el individuo, la cultura desarrolla su propio super-yo, bajo suya influencia se produce la evolución cultural. Sus características son las siguientes:

- «(...) tiene un origen análogo al del super-yo individual, pues se funda en la impresión que han dejado los grandes personajes conductores» ${ }^{83}$.

- «(...) a entera semejanza del individual establece rígidos ideales cuya violación es castigada con la 'angustia de conciencia'» ${ }^{84}$.

- «El super-yo cultural ha elaborado sus ideales y erigido sus normas. Entre éstas, las que se refieren a las relaciones de los seres entre sí están comprendidas en el concepto de la ética» ${ }^{85}$.

-El super-yo cultural «acepta (...) que el yo goza de ilimitada autoridad sobre su ello» ${ }^{86}$. Pero «la dominación sobre el ello no puede exceder determinados límites (...). La cultura se despreocupa de todo esto, limitándose a decretar que cuanto más difícil sea obedecer el precepto, tanto más mérito tendrá su acatamiento» ${ }^{87}$.

Para Freud, el rumbo de la historia vendrá determinado por una cuestión: «si el desarrollo cultural logrará hacer frente a las perturbaciones de la vida colectiva emanadas de instinto de agresión y autodestrucción» ${ }^{88}$. Y, al menos en el texto que analizamos, no se define por una u otra opción. Nos espera el paraíso o el infierno, y depende de nosotros, de ese equilibrio que, quizás, podamos alcanzar algún día. Así pues, brevemente hemos visto ese concepto central en el análisis de la sociedad: el concepto de angustia y de sentimiento de culpabilidad. El análisis de sus características y de su origen nos ha llevado a contemplar la lucha entre el instinto del individuo y la presión social que lo coarta, generando agresividad, generando un super-yo (tanto individual como cultural) que internaliza esa agresividad y que da lugar a la angustia y al sentimiento de culpabilidad. Como ya resaltamos en uno de los párrafos citados, el progreso de la cultura conlleva, a los ojos de Freud, un aumen-

82. Idem, o.c., p. 3.065 .
83. Idem, o.c., p. 3.065 .
84. Idem, o.c., p. 3.065 .
85. Idem, o.c., p. 3.065 .
86. Idem, o.c., p. 3.066 .
87. Idem, o.c., p. 3.066 .
88. Idem, o.c., p. 3.067 . 
to de ese sentimiento, aumento que cada vez será más difícilmente soportable. A pesar de todo, esta dinámica no es inevitable, por cuanto conocemos la fuerza del instinto y los límites, que no se pueden rebasar, del 'ello', estando en las manos de la humanidad la posibilidad de reconducir esa tensión hacia el equilibrio. Aunque..., tal como se expresa Freud, el duelo lleva trazas de ser eterno, y por lo tanto la felicidad del hombre, que este persigue con tanto ahínco, se convierte en una ilusión en la que se proyectan las frustraciones y con cuya ensoñación los hombres se consuelan.

Este panorama constituye un contexto para análisis concretos de fenómenos sociales, y en buena medida está en la base del pesimismo que embargó a partir de la década de 1940 a Horkeimer y Adorno. Como tal 'marco' impone una explicación de fondo, proporciona un 'sentido' determinado. Freud no es totalmente mecanicista, al dejar una labor a nuestro 'yo' consciente: la búsqueda del equilibrio; pero sí es mecanicista en la concepción de ese equilibrio, y el conflicto del que surgen los desequilibrios es necesario porque pertenece a la misma naturaleza humana. Por esta razón es importante partir de los límites reales del individuo y de las exigencias del ello, a pesar de que el mismo individuo se encuentra dividido entre el afán egoísta y el afán altruista de unión con los demás.

Fromm critica los presupuestos del análisis de Freud en los siguientes términos: el punto de vista freudiano se caracteriza por afirmar que «los fenómenos culturales arraigan en factores psicológicos derivados de impulsos sensitivos que, en sí mismos son influidos por la sociedad sólo a través de algún grado de represión. Siguiendo esta línea interpretativa, los autores freudianos han explicado el capitalismo como una consecuencia del erotismo anal, y el desarrollo de la cristiandad primitiva como resultado de la ambivalencia frente a la imagen paterna» ${ }^{89}$. Es especialmente destacable que Freud «se sentía predispuesto a interpretar todos los motivos 'ideales' del hombre como originados en algo 'vil'» ${ }^{90}$, frente a la afirmación de Fromm de que ideales como los de libertad y verdad «puedan (...) representar tendencias genuinas y que todo análisis que no tenga en cuenta estos impulsos como factores dinámicos se halla destinado al fracaso» ${ }^{91}$. Por otra parte, la psicología de Freud es una psicología de la escasez: «los fenómenos de abundancia, como el amor o la ternura, en realidad no desempeñan ninguna función dentro de su sistema» ${ }^{92}$. $\mathrm{Y}$ esto es un grave desconocimiento de la realidad, tanto individual como cul-

89. Е. FromM, El miedo a la libertad, o.c., p. 342.

90. Idem, o.c., p. 340.

91. Idem, o.c., p. 341.

92. Idem, o.c., p. 341. 
tural humana. No se puede reducir el universo del hombre a la lucha entre el instinto egoísta y la necesidad social de moderar ese instinto.

Habermas sintetiza del siguiente modo el análisis freudiano sobre la sociedad y su futuro: «Entre los presupuestos de la teoría freudiana no figura la promesa de que el desdarrollo de las fuerzas productivas pueda librar de su carácter represivo al marco institucional, ni tampoco que haya que rechazar en principio tal esperanza. Freud ha precisado el sentido de una historia de la especie, que está determinada por un proceso de autoproducción bajo categorías del trabajo y por un proceso de formación bajo las condiciones de una comunicación distorsionada (...) la meta es la 'fundamentación racional de los preceptos de la cultura', es decir, la organización de las relaciones sociales según el principio de que el valor de toda norma implique consecuencias políticas ha de depender de un consenso brotado en una comunicación libre de violencia (...). Esta precaución (...) impide (...) la certeza totalitaria (...). Freud da a la dominación y a la ideología fundamentos demasiado profundos como para que pudiera prometer seguridad, en lugar de una lógica de la esperanza fundada y del ensayo controlado" ${ }^{93}$. Pero, a pesar de esta 'lógica de la esperanza', la reducción biologicista de Freud y su psicología de la escasez diseñan un futuro nada halagüeño. Habermas señala que el modelo biológico de Freud es 'precrítico'. Y esa lucha vana que nos propone como imagen de la auténtica realidad, entre Eros y el impulso a la muerte, nos condena a una vivencia permanente de la culpa, aunque... no descarte que logremos algún día el equilibrio perdido, equilibrio siempre precario.

\subsection{La escuela de Frankfurt: el pesimismo práctico}

La escuela de Frankfurt, a pesar de su dilatada existencia, no produjo una teoría uniforme acerca de la sociedad. Más aún, a partir de los años cuarenta la distancia teórica entre Marcuse y Adorno y Horkheimer, fue haciéndose mayor. Sin embargo, realizaron un análisis de la sociedad de su tiempo y de los principales mitos y peligros presentes en esa sociedad.

El análisis de esta escuela, y principalmente de su inspirador, Horkheimer, parte de la negación de la identidad, de la negación del discurso dogmático y unitario. A partir de aquí, resaltan siempre el aspecto negativo y dialéctico del pensar para evitar y delatar ese peligro. En el fondo del análisis de la 'razón instrumental' y de la Ilustración, está la denuncia de esa tendencia al reduccionismo y a la identidad alienadora. $Y$ es en esa tendencia en la que se encuentra nuestra sociedad actual, debatiéndose: «En la base del mito del ilu-

93. J. HABERMAS, Conocimiento e interés, o.c., p. 279. 
minismo he visto siempre antropomorfismo, la proyección de lo subjetivo sobre la naturaleza (...). Las diversas figuras míticas son todas reductibles, según el iluminismo, al mismo denominador, es decir, al sujeto (...). El iluminismo reconoce a priori, como ser y acaecer, sólo aquello que se deja reducir a una unidad; su ideal es el sistema, del cual se deduce todo y cualquier cosa» ${ }^{94}$. «El iluminismo es totalitario» ${ }^{95}$. Para Horkheimer y Adorno, «la lógica formal ha sido la gran escuela de la unificación (...). La sociedad burguesa se halla dominada por lo equivalente. Torna comparable lo heterogéneo reduciéndolo a grandezas abstractas (...). Se continúa exigiendo la destrucción de los dioses (...). Pero los mitos que caen bajo los golpes del iluminismo eran ya productos del mismo iluminismo. En el cálculo científico del acontecer queda anulada la apreciación que el pensamiento había formulado en los mitos respecto al acontecer» ${ }^{96}$.

Es este punto de partida, clave del análisis de la escuela de Frankfurt, el que conviene destacar y el que lleva, a la postre, a un inevitable pesimismo práctico. En esta toma de postura, Horkheimer y los pensadores de la escuela de Frankfurt adoptaron lo que más tarde les caracterizaría: el cultivo de la dimensión negativa, crítica, de lo existente. Desde aquí analizaron la Ilustración y la sociedad actual, y desde aquí descubrieron los nuevos mitos y la opresión de la razón instrumental, la pérdida de significado de la realidad, que da pie a los totalitarismos. Precisamente la defensa de la subjetividad individual se retrotrae en Horkheimer a la lectura de Kant: «la lectura de Kant ayudó a Horkheimer a desarrollar su sensibilidad frente a la importancia de la individualidad, como un valor que nunca debiera ahogarse enteramente bajo las demandas de la totalidad ${ }^{97}$. Frente a Hegel, Horkheimer repudia la teoría de la identidad: «Para Horkheimer, todos los absolutos, todas las teorías de identidad eran sospechosas. Incluso el ideal de justicia absoluta contenido en la religión (...) tiene una cualidad quimérica (...). Como resultado, la filosofía, tal como él la comprendía, expresa siempre una inevitable nota de tristeza, pero sin sucumbir a la resignación» ${ }^{98}$.

Manteniéndose en una postura de equilibrio, rechazó la disyuntiva entre sistematización metafísica o empirismo antinómico: «Abogó (...), por la posibilidad de una ciencia social dialéctica que evitaría una teoría de la identidad y, sin embargo, preservaría el derecho del observador a ir más allá de los datos

94. M. Horkheimer; T.W. Adorno, Dialéctica del iluminismo, Buenos Aires, Ed. Sur 1971, p. 19.

95. Idem, o.c., p. 19.

96. Idem, o.c., p. 20.

97. M. MARTIN JAX, La imaginación dialéctica, o.c., p. 90.

98. Idem, o.c., pp. 92-93. 
de su experiencia» ${ }^{99}$. Esta comprensión dialéctica que se resiste a absolutizar un polo queda de manifiesto en las críticas de Horkheimer a los lebensphilosophen: éstos habían minimizado la importancia de la acción en el mundo histórico, y parecía que rechazaban la razón en sí misma, tendiendo a olvidar la dimensión material de la realidad y exagerando sus ataques.

A pesar de esta dimensión crítica, a pesar de la imposibilidad de alcanzar un conocimiento absoluto, «Horkheimer sostenía que el materialismo no debía sucumbir en una resignación relativista» ${ }^{100}$. Realzó el elemento activo en el conocimiento: «los objetos de percepción, afirmó, son el producto de las acciones humanas, aunque la relación tiende a ser enmascarada por la reificación» ${ }^{101}$. De aquí que el verdadero materialismo sea dialéctico, involucrando un proceso dinámico de interacción entre sujeto y objeto. Esta dialéctica no pretendía descubrir principios ontológicos fundamentales. La interacción constante entre lo particular y lo universal resaltaba «la importancia crucial de la mediación para una teoría correcta de la sociedad» ${ }^{102}$. La relación entre la totalidad y sus momentos es recíproca. Por eso la relación de la cultura con la subestructura materia de la sociedad era multidimensional. Precisamente, al realzar la totalidad quedaba de manifiesto la fetichización en ciertos análisis sociales, que primaban una faceta. O en cierto tipo de razón, que defendía un sólo tipo de discurso sobre la realidad, el 'instrumental'.

El fetichismo no afecta sólo a la absolutización del instrumento burgués. También existe en la tentación de describir el 'paraíso' desde la situación necesitada actual; también afecta al trabajo. «El antagonismo de Horkheimer hacia la fetichización del trabajo expresaba otra dimensión de su materialismo: la exigencia de una felicidad sexual, humana» ${ }^{103}$. La ideología del deber y del servicio a la totalidad es otro fetiche a combatir: «En contraste con la ética burguesa de la abnegación, Horkheimer mantuvo siempre la dignidad del egoísmo (...). Su individuo egoísta (...) siempre alcanzaba su mayor gratificación a través de una interacción comunal (...). Horkheimer desafió constantemente la reificación del individuo y de la sociedad como polos opuestos, así como negó la mutua exclusividad de sujeto y objeto en la filosofía” ${ }^{104}$. En su defensa de la razón, comprobará el resultado a que conduce el fetichismo de los hechos: «El positivismo, bajo cualquiera de sus formas, significaba en últi-

99. Idem, o.c., p. 93.

100. Idem, o.c., p. 102.

101. Idem, o.c., p. 102.

102. Idem, o.c., p. 103.

103. Idem, o.c., p. 108.

104. Idem, o.c., p. 109. 
ma instancia la abdicación de la reflexión. El resultado era la absolutización de los 'hechos' y la reificación del orden existente»' ${ }^{105}$.

Así pues, observamos el lugar desde el que brota la reflexión de los pensadores de la escuela de Frankurt: el rechazo de la lógica de la identidad y del absoluto consiguiente, y la afirmación de una dialéctica que pretende salvaguardar tanto al objeto como al sujeto, sin caer en la pretensión de verdades absolutas. La Escuela de Frankfurt se negó a formular positivamente los ideales (a excepción del último Marcuse), y eligió esa dimensión radical y negativa del pensamiento, que cada vez encontraría más dificultades para definir la praxis más adecuada a la propia teoría. Respecto a la relación entre razón y praxis, resaltamos dos puntos:

- «La Teoría Crítica tenía un concepto básicamente insustancial de la razón y la verdad, arraigado en condiciones sociales y a la vez fuera de ellas, conectado con la praxis y no obstante guardando las distancias respecto de ésta» ${ }^{106}$.

1. «Verdadero es todo aquello que promueve un cambio social en la dirección de la sociedad racional» ${ }^{107}$.

2. Nunca explicitarán ese concepto de razón. La sociedad óptima era aquella en la que el hombre «estaba libre para actuar como sujeto antes que para ser actuado como un predicado contingente» ${ }^{108}$. Más allá de esto, «sólo Marcuse intentó articular una antropología positiva en un momento dado de su carrera» ${ }^{109}$.

-Praxis y razón eran los dos polos de la Teoría Crítica, aunque la primacía de la razón nunca estuvo en duda. El énfasis sobre la praxis se unía al rechazo de la teoría de la identidad de Hegel. Y «en los espacios creados por las mediaciones irreductibles entre sujeto y objeto, particular y universal, podía sustentarse la libertad humana» ${ }^{110}$.

Después de la II guerra mundial, cedió el interés por la praxis para pasar a centrarse (el Institut) en el análisis de la desaparición de las fuerzas críticas, negativas, de la sociedad: se centró el análisis en la superestructura cultural de la sociedad moderna. El libro de Horkheimer y Adorno que citamos al comenzar el apartado correspondiente a esta época, en la que se critica la desaparición de la posibilidad de crítica ( $\mathrm{y}$, por lo tanto de avance) al suprimirse las fuerzas críticas o negativas de la sociedad.

105. Idem, o.c., p. 115.

106. Idem, o.c., p. 117.

107. Idem, o.c., p. 117.

108. Idem, o.c., p. 107.

109. Idem, o.c., p. 106.

110. Idem, o.c., p. 119. 
Hacia la década de 1940, la Escuela de Frankfurt comenzó a tener serias dudas sobre el proyecto inicial, la unidad de teoría y práctica revolucionaria: «las mediaciones entre su teoría y tanto la investigación empírica como la praxis política se hacían cada vez más problemáticas» ${ }^{111}$. El énfasis se trasladó hacia la relación oculta entre el hombre y la naturaleza: sustituyó a la lucha de clases como motor de la historia; el conflicto entre el hombre y la naturaleza, exterior e interior, asume su papel ${ }^{112}$. La evolución tiende a la melancolía: a medida que la teoría se volvía más radical, el Institut se encontró con menos fuerzas para hallar una praxis radical adecuada. La dominación asumía nuevas caras, formas no económicas, más directas. Horkheimer se retrotrae al Renacimiento: «La nueva concepción del mundo natural como un campo de control y manipulación humana (...) correspondía a una noción similar del hombre mismo como un objeto de dominación» ${ }^{113}$. A partir de este momento, dejaron de buscar las respuestas a los problemas culturales en la infraestructura material, económica, de la sociedad. Incluyen a Marx en la crítica de la Ilustración: «El énfasis excesivo de Marx sobre la centralidad del trabajo (...) fue la razón primaria para este argumento. Implícita en la reducción del hombre a un animal laborans (...) estaba la reificación de la naturaleza como un campo para la explotación humana» ${ }^{114}$.

El pesimismo no era total: «A pesar de su desconfianza ante las teorías de identidad absolutas, Horkheimer y sus colegas subrayan la importancia de la 'razón objetiva'como un antídoto frente al ascendiente unilateral de una razón 'subjetiva' instrumentalizada» ${ }^{115}$. Pero, a pesar del leitmotiv de la reconciliación de la Vernunft, Horkheimer y Adorno no abandonarán nunca su negativa a describir el 'otro', el futuro paraíso que al ser descrito se convertiría en una nueva fuente de dominación y absolutismo, reificándose. Bajo condiciones sociales alteradas drásticamente, la filosofía sólo podía realizar un limitado papel: «el principio del naufragio de la negación nos lleva a intentar salvar verdades relativas del naufragio de las verdades absolutas» ${ }^{116}$. «El refugio real de la verdad era la negación» ${ }^{117}$.

111. Idem, o.c., p. 409.

112. En este cambio de orientación hay un motivo de fondo: la crisis del concepto marxista de un sujeto revolucionario único y definitivo, el proletariado, concepción incompatible con la experiencia histórica del socialismo 'real', y con la crítica de la lógica de la identidad, pilar inconmovible de la Teoría Crítica. Expresa la crisis de la confianza en el poder salvador, mesiánico, soteriológico del proletariado industrial concebido por Marx, inexistente como clase compacta en la sociedad del siglo XX, sumamente estratificada. Cfr. J. JiméneZ, Filosofía y emancipación, o.c., pp. 253-266.

113. Idem, o.c., p. 415.

114. Idem, o.c., p. 418.

115. Idem, o.c., p. 419.

116. Idem, o.c., p. 424.

117. Idem, o.c., p. 424. 
Dada la destrucción en la sociedad actual de los elementos de subjetividad; la individualidad genuina va declinando su existencia a un ritmo alarmante. La existencia de contradicciones lleva camino de desaparecer: «Sin un mandato claro para la acción, el único curso abierto para quienes todavía podían escapar al poder embrutecedor de la industria cultural consistía en preservar y cultivar los vestigios de negación que aún quedaban» ${ }^{118}$. El contraste entre la utopía a la que no se puede renunciar, para evitar que el mito seduzca a la Historia, y la invada, y la imposibilidad de que se materialice esa utopía, dado que las exigencias de la totalidad «no podían cumplirse sin la destrucción de lo finito y contingente» ${ }^{119}$, nos deja en la indefinición, y en la paradoja, respecto a la acción.

Esta evolución, desde la insistencia inicial en la praxis hasta la indefinición práctica, revela dos cosas:

-En primer lugar, las visiones utópicas son en este segundo momento un medio para lograr el distanciamiento crítico necesario frente a la atracción de la realidad social existente; ya no son programas para transformar la realidad, sino medios para poder observar críticamente esa realidad.

-En segundo lugar, esta transformación obedece a que «con el desplazamiento del énfasis del Institut desde la lucha de clases hacia el conflicto entre el hombre y la naturaleza, desapareció la posibilidad de un sujeto histórico capaz de anunciar la era revolucionaria. El imperativo de una praxis (...) ya no era una parte integrante de su pensamiento" ${ }^{120}$. La realidad fundamental era que «la negación nunca podría ser verdaderamente negada» ${ }^{121}$. La Escuela de Frankfurt escogió la razón en su forma negativa como única forma de praxis accesible a los hombres honestos.

Así pues, tras exponer brevemente la causa del pesimismo (que refleja una cierta concepción social) y los fundamentos del discurso negativo de la Escuela de Frankfurt, a saber, la negación de la lógica de la identidad, la dialéctica entre sujeto-objeto y razón-praxis, y la búsqueda de una razón y una praxis que realizara al sujeto en cuanto tal, inmerso en la dialéctica (en una primera etapa en la lucha de clases sociales, y en una segunda etapa en la relación Hombre-Naturaleza), habiendo criticado el fetichismo y los mitos presentes en la sociedad actual y en la Ilustración, nos encontramos con una esbozo de sociedad, con una comprensión previa que ubica los hechos de forma distinta al liberalismo, al marxismo vulgar o a la ortodoxia freudiana. Nos encontra-

118. Idem, o.c., p. 445.

119. Idem, o.c., p. 448 .

120. Idem, o.c., p. 449.

121. Idem, o.c., p. 449. 
mos con un pensamiento que hace resaltar las carencias y limitaciones de la sociedad actual, una forma de caminar hacia una vida, si no mejor, sí más consciente y autodeterminada. Una lucidez que prefiere el pesimismo y la nostalgia frente al dogmatismo. Y no la nostalgia del pasado, sino la nostalgia de una vía para alcanzar la praxis adecuada y esa razón dialéctica que revela su sombra en la crítica negativa de lo existente.

Algunos autores se oponen al pesimismo explícito de las reflexiones de los miembros de la Escuela de Frankfurt sobre la sociedad actual. Horkheimer sintetiza esa situación, y su futuro, con las siguientes palabras: «Cuanto más automáticas y cuanto más instrumentalizadas se vuelven las ideas, tanto menos descubre uno en ellas la subsistencia de pensamientos con sentido propio»" ${ }^{122}$. Nuestra sociedad se caracteriza, pues, por la falta de 'sentido propio', de substancia, de verdad: «(...) pues la verdad no es un fin en sí misma” ${ }^{123}$. Sin embargo, autores como E. Carr acusan a los intelectuales 'pesimistas' de ser la conciencia de una clase que ha perdido el poder: «En primer lugar, el diagnóstico de acuerdo con el cual no hay esperanzas para el futuro, si bien se pretende fundado en hechos irrefutables, es un constructo teórico abstracto. La inmensa mayoría de la gente simplemente no cree en él; y este no creer se manifiesta en su conducta» ${ }^{124}$. El pesimismo suele llevar a la inactividad, aunque hay que señalar que los miembros de la Escuela de Frankfurt siempre han intentado no caer en ese extremo. Si merece la pena luchar, porque sólo se vive una vez, y hay objetivos que podemos alcanzar, es que existe una posibilidad de mejora, es que hay algo por lo que luchar, es que el hombre se realiza en el intento, y su vida se verifica por el volumen de acción (espiritual o material) que intenta y que culmina. La vida misma, en la experiencia cotidiana, nos da un motivo. Ciertamente el peso de la concepción freudiana influyó grandemente en Horkheimer y Adorno. Como es obvio, ese motivo que surge de la vida y que convertimos en algo real en nuestra lucha, no es un mero voluntarismo. Es un afán de realización que podemos describir, y que fundamenta las dimensiones positivas, alegres, de la vida individual y social. Según E. Carr, «la idea de una pronta aniquilación está limitada a un grupo de intelectuales malhumorados (...) la actual ola de escepticismo y desesperación, (...) es una forma de elitismo. (...). Los principales abanderados de este movimiento son los intelectuales, los proveedores de ideas del grupo social rector al cual sirven» ${ }^{125}$. Según $\mathrm{E}$. Carr, es significativo que tales intelectuales

122. M. HorkHeImer, Crítica de la razón instrumental, Buenos Aires, Ed. Sur 1969, p. 33.

123. Idem, o.c., p. 33.

124. E.H. CARR, ¿Qué es la historia?, Barcelona, Ariel 1987, pp. 12-13.

125. Idem, o.c., pp. 13-14. 
pertenezcan a Europa, fuente de ese pesimismo, causado por su pérdida de hegemonía... No comparto enteramente la crítica de E. Carr al pesimismo de la Escuela de Frankfurt, aunque puede ser aplicable al pesimismo europeo general del siglo XX. Por otra parte, Carr no critica directamente a la Escuela de Frankfurt, sino a ese estado de ánimo tan frecuente en la obra de los intelectuales europeos. De cualquier forma, la crítica de E. Carr ilumina otro aspecto del problema.

Finalmente, quisiera resaltar la importancia de la reflexión de los autores de la Escuela de Frankfurt, ya que su lucidez 'negativa' es un arma que nos preserva de la adhesión fácil al mito o al absoluto tan frecuente en la historia contemporánea, así como de la falsa imagen de felicidad y 'realización' que campa por sus respetos en la publicidad de cualquier signo político o económico.

\section{CONCLUSIÓN}

\section{El sentido de los datos}

Hemos observado en los análisis anteriores cómo cada autor aporta una explicación de los datos (a veces complementarias), y cómo dibujan una comprensión de lo existente, otorgando un sentido a la realidad que les rodea. A pesar de su intención, en los que la tengan, supuestamente científica, estos autores proponen un modo de entender las cosas, (y por lo tanto un modo de vida), ofrecen una explicación del porqué y, a veces, del para qué. Por eso podemos constatar la presencia de una teleología manifiesta en Marx, o el pesimismo práctico de Horkheimer (basado en la imposibilidad de encontrar un supuesto básico de Marx, a saber, un sujeto revolucionario uniforme, con carácter unitario y de clase, un proletariado 'redentor'). A partir de la tradición intelectual y científica anterior a ellos, y tomando como punto de partida la realidad social, estos autores llegan a comprensiones distintas. De hecho, tanto Fromm como Marcuse, Adorno y Horkheimer intentarán una combinación de marxismo y psicoanálisis. Sin embargo, ninguno (excepto Adorno y Horkheimer) llegó a responder a preguntas similares de forma igual.

La exposición anterior nos ha abierto perspectivas plurales: hay una gran variedad de puntos de vista desde los que se parte para analizar la sociedad humana. La complejidad de los datos es mucho mayor cuando éstos se estructuran en torno a cuestiones de 'significado'. Aquí ya no vale una interpretación monolítica o lineal; la respuesta a las carencias sociales y a la cuestión del devenir no es fácil: esa dificultad es la que llevó a la Escuela de Frankfurt a un pesimismo teórico sustentado en su rechazo de la teoría de la identidad.

Sin embargo, la necesidad no sólo de análisis, de exposición de datos, si- 
no de interpretación, de comentario sobre el significado, subsiste en el análisis social. Incluso interpretaciones supuestamente científicas, siempre esconden una propuesta, y por lo tanto una clave de sentido, clave que, normalmente, tiene una conexión con los datos más voluntaria que necesaria. La autorreflexión de las Ciencias Sociales es importante porque esclarece el componente previo, y por lo tanto ideológico y relativamente a priori, que tiñe muchos estudios y muchas propuestas.

Es necesario 'interpretar'; esa interpretación (de diferentes signos y que parte de diferentes puntos de vista previos) se manifiesta en la valoración de las encuestas, en los comentarios periodísticos a la actualidad social, en la proyección de puntos de vista (y en la defensa de éstos). Incluso al elegir una explicación intencional o causal de los fenómenos investigados por las Ciencias Sociales, observamos una toma de postura previa, que tiene consecuencias metodológicas y explicativas. Una conciencia crítica de los métodos tiene que sacar a la luz este componente ideológico del razonamiento. En los autores estudiados hemos observado dos posturas que apelan a desarrollos necesarios e inevitables, causales (Marx y Freud), y hemos presentado dos posturas que dejan abierta la posibilidad de diversos futuros (con tendencias optimistas -Fromm - o pesimistas - la Escuela de Frankfurt-), posturas que eliminan la necesidad del curso futuro y del curso pasado de la historia. Ambas conclusiones surgen de sus puntos de partida y de las concepciones mecanicistas (en el sentido de que hay un desarrollo necesario, en un caso la dialéctica de la lucha de clases y en el otro el surgimiento del sentimiento de culpabilidad) o más bien no-mecanicistas de unos y otros. Precisamente la dificultad de proponer una praxis concreta, salvadora, llevó a la Escuela de Frankfurt al pesimismo práctico. También hemos indicado el mutuo influjo de unos autores sobre otros (como Freud influye en la Escuela de Frankfurt, siendo una causa de su tendencia al pesimismo, y como los matices utópicos y finalistas, soteriológicos, de Marx influyeron en el optimismo relativo de Fromm).

Coincidimos con Habermas al plantearnos la tarea de la autorreflexión del conocimiento como algo ineludible, y como algo liberador. La conciencia reflexiona sobre sí misma, y sólo se libera en cuanto entiende, en cuanto supera los correajes ideológicos y afectivos, retóricos y de poder. La necesidad de un 'sentido', del factor simbólico, la exigencia que del mismo realiza la sociedad, tiene su expresión en las propuestas de las teorías. Al elegir el problema, el científico social ya configura en parte la respuesta, y la estructura según patrones previos ${ }^{126}$. Que esta configuración quede abierta a modificaciones o

126. Hanson realizó una notable investigación sobre los de la carga teórica del lenguaje: «Hanson está manteniendo aquí la idea de una dependencia del significado, idea, según la cual, el 
que se empeñe en ajustar la realidad a sus ideas es una cuestión fundamental, porque separa el dogma del pensamiento crítico, pensamiento que desde una perspectiva se abre a la pluràlidad de lo real. La manipulación de los datos, de las estadísticas, es posible porque la explicación del sentido de los mismos es algo en lo que interviene activamente la ideología del analista que efectúa el estudio. Un caso extremo de ideologización es el protagonizado durante dos décadas por T.D. Lysenko ${ }^{127}$. Un ejemplo más cotidiano consiste en observar la diferente perspectiva de la guerra civil española en la 'Vida de Franco', dirigida por Ricardo de la Cierva, en relación con la perspectiva que ofrece de la

significado de los términos es una función de los esquemas conceptuales de los que forman parte. (...). Pero todas las teorías of recen explicaciones y, por consiguiente, un modelo de organización conceptual. La idea de Hanson es, sin lugar a duda ninguna, que este análisis de la dependencia del significado hecho en relación con las teorías causales es arquetípico para todas las teorías. (...). Poseer o entender una teoría es organizar conceptualmente los datos. (...). El significado de una palabra depende del contexto. En la medida en que una palabra pueda tener una carga explicativa en un contexto determinado, dicha palabra debe formar parte de un modelo de organización conceptual dentro de ese contexto». Frederick Suppe, La estructura de las Teorías Cientificas, Madrid, Editora Nacional 1979, pp. 191-193. Es importante analizar el horizonte significativo en el que situamos los datos, desde el cual interpretamos, y que podemos superar. El influjo de estos a prioris es más visible y notable en los seguidores o discípulos de las grandes escuelas o teorías sociológicas, en los comentaristas de prensa, que en autores como Marx o Fromm, que en gran medida organizan un nuevo 'horizonte' o 'campo' de sentido de los datos, un nuevo esquema donde encuadrarlos. Conforme más reflexivo es un individuo, y más independiente es del marco en el cual se formó y habita, y más capaz es de reformarlo. El dogmatismo surge cuando se absolutizan esos puntos de partida.

127. «T.D. Lysenko fue un agrónomo que, a partir de finales de los años veinte y principio de los treinta, desarrolló una serie de afirmaciones tebricas en biología y de propuestas prácticas para la agricultura que implicaban el rechazo de la genética moderna. La sustituyó por su 'teoría del desarrollo fásico de las plantas', según la cual es posible, en ciertas fases en la vida de una planta, 'destruir' su herencia y sustituirla por una nueva, cambiándose, por tanto, una especie por otra. Junto con su colaborador, I.I. Prezent, Lysenko emprendió un ataque contra la biología establecida en el que su arma principal era la demagogia política, catalogando a sus oponentes como abogados de la 'ciencia burguesa' el 'idealismo', el 'trotskismo', etc. Mediante una variedad de circunstancias, incluida la estructura del sistema político e industrial soviético, el hecho de que lograra ganarse el favor de Stalin, y una crisis agrícola, Lysenko consiguió un control absoluto sobre la biología soviética. Fueron detenidos muchos científicos adversarios, otros perdieron sus trabajos, de 1948 a 1953 la investigación y la enseñanza de la genética fueron prohibidas, y los libros de texto de biología se escribieron de nuevo de acuerdo con la 'nueva biología'. Los partidarios de Lysenko continuaron controlando las universidades y las revistas científicas hasta bien entrados los años sesenta». HAROL I. BRown, La nueva filosofía de la ciencia, Madrid, Tecnos 1988, p. 211. Lo terrible de este ejemplo es la situación completamente ideologizada y dogmática que permitió que se conviertiese en una realidad. Todo lo que no se conforme con la ideología del poder, no es científico, y se elimina. Aquí observamos una deformación del pensamiento y de la acción, en la cual sólo es válido lo que se ajusta a nuestro esquema previo, en el caso del marxismo vulgar 'supuestamente científico'. No creo que el afán marxista, enormemente válido, de lograr la superación de la alienación del hombre en la sociedad, se consiga creando estructuras sociales y de poder, y discursos teóricos, que hagan posible estos excesos. 
misma Tuñón de Lara en la Historia de España dirigida por él ${ }^{128}$. Y ambos utilizan métodos estadísticos, etc. De aquí la honestidad intelectual de los pensadores de la Escuela de Frankfurt, como Horkheimer y Adorno, que siempre se negaron a formular un proyecto positivo, para no quedar presos de una utopía que se vuelve dogmática al presentarse como futuro único, o necesario, o inevitable, o soteriológico. Permanecieron en la dimensión crítica, negativa, negando la identidad, el monopolio de un pensamiento o de una alternativa: «Horkheimer y Adorno no abandonaban su negativa a nombrar o a describir el 'otro', que como hemos visto era una de las premisas centrales de la Teoría Crítica desde el principio (...). El fracaso mayor de la mentalidad de la Ilustración (...) fue (...) su eliminación sistemática de la negación en el lenguaje. Esta fue la razón de que su sustitución de fórmulas por conceptos resultara tan destructiva (...). Así el lenguaje (...) llegó a ser unidimensional. Incapaz de expresar la negación, ya no podía vocear la protesta de los oprimidos. En vez de revelar significaciones, el discurso se había convertido sólo en un instrumento de las fuerzas dominantes en la sociedad (...). El hombre occidental había, en efecto, perdido su identidad, así como el lenguaje capaz de conceptualización y negación había sido sustituido por un lenguaje capaz solamente de actuar como un instrumento del statu quo» ${ }^{129}$.

Esta actitud crítica pone al descubierto la carga ideológica que se proyecta en numerosos análisis de la realidad social, y que por lo tanto, no son tan 'verdaderos' o 'científicos' como se puede pretender, sino sólo opciones fundamentadas en la coherencia de su discurso argumentativo..., en el mejor de los casos. El tipo de verdad que se plantea al dar un sentido a los datos no es aristotélica, «adaequatio rei et intellectus», porque no hay algo obvio que se pueda describir obviamente, sino que lo que se da es una aproximación argumentativa, falible (hablamos de cuestiones de sentido, unidas al diseño de lo que queremos ser y realizar, unidas al futuro, no determinadas y criticables), intersubjetiva, que lleva implícita una propuesta futura que ha de ser enjuiciada precisamente desde el horizonte que propone (si es liberador y equitativo, $o$ si no lo es) y desde sus fundamentos tanto científicos como precientíficos, ideológicos. Enlazamos aquí con la distinción efectuada por Apel entre 'constitución de sentido' y 'reflexión de validez': «el sentido (...) se basa (...) en la posibilidad de fundamentación argumentativa de una pretensión de validez criticable» ${ }^{130}$.

128. Cfr. Ricardo de la Cierva, Vida de Franco, Madrid, ABC; TuÑón DE LARA, (dir.), Historia de España, vol. IX, Barcelona, Labor 1986, pp. 243-529.

129. MARTIN JAY, La imaginación dialéctica, o.c., pp. 423-425.

130. J. Habermas, Conocimiento e interés, o.c., p.310. 
Naturalmente, hay algunas argumentaciones más potentes y coherentes que otras. La pluralidad que deviene al admitir ese status de las explicaciones sobre el sentido de los datos no aboca en un relativismo, sino en un esfuerzo crítico y en un afán de fundamentación racional en un discurso intersubjetivo. El problema surge cuando se formula la identidad de la verdad y la bondad con una realidad determinada, o con una teoría determinada, o con un sistema político determinado, o con un proyecto específico. Aquí encontramos una absolutización que se erige contra la realidad que afirma querer mejorar... A una identificación de este tipo ya no se le puede dar el carácter de 'científica', sino sólo mostrarla como una opción ético-político-social, susceptible de crítica y más rechazable y falsa cuanto más absolutista, escatológica y redentora sea.

Todas las opciones de sentido (y empleo la palabra 'opción' para resaltar su carácter no-determinado, no-científico en el sentido de deducible necesaria y únicamente de la realidad) se retrotraen, en sus proyectos y afirmaciones simbólicas y de sentido, al horizonte diseñado implícita o explícitamente por sus conceptos claves, previos, no demostrables. En la historia de la filosofía observamos cómo los grandes autores han roto los límites del pensamiento de los autores anteriores, diseñando en cierta medida un 'horizonte' nuevo... Los científicos sociales dependen en su interpretación y valoración de las cuestiones de significado y sentido de las teorías de que participan, a no ser que creen ellos una nueva. Esas teorías se articulan en torno a conceptos 'clave', en torno a ejes de pensamiento a intuiciones innovadoras. Es esta relatividad la que quería resaltar, y este movimiento en el que se fundamenta el discurso sobre el sentido en el marco teórico elegido, lo que quería destacar en el enfoque de este trabajo, analizando algunas claves del pensamiento de ciertos autores fundamentales en la interpretación y la concepción del mundo en diversas corrientes de las Ciencias Sociales.

\section{La crítica de las ideologías}

Hemos analizado la 'carga teórica' que lleva toda interpretación y explicación de los datos en torno a las cuestiones de 'sentido', en torno al mundo simbólico y al diseño del futuro. Hemos analizado como unas líneas fundamentales recorren el pensamiento de los autores, determinando en cierta medida sus conclusiones y el alcance de su razonamiento. Tras estudiar a Fromm, Freud, Marx y Horkheimer, especificamos algunas características relativas a la aportación de sentido que los hombres realizamos al explicar la realidad: la concebimos y explicamos según las teorías que defendemos; expusimos también la capacidad para superar la teoría inicial que configura nuestras teorías y respuestas, señalando esta visión crítica como una de las tareas fundamentales 
de la autorreflexión filosófica sobre las Ciencias Sociales. Finalmente, mencionamos alguno de los excesos posibles en los que el hombre puede caer, dadas las características de esta dinámica en la que el hombre aporta un sentido y un futuro a la realidad; recordemos el caso Lysenko. En conformidad con el desarrollo de nuestra investigación, ahora nos enfrentamos con el problema de las ideologías y su relación con los métodos de investigación social:

- «En tanto que los hombres obran, (...) proceden a desarrollar una variedad de métodos para la penetración experimental e intelectual del mundo en que ellos viven que nunca han sido analizados con la misma precisión que los llamados modos exactos de conocer (...) en los tiempos modernos dependen muchas más cosas del pensar correctamente de acuerdo con una situación determinada que en sociedades anteriores. La significación del conocimiento social crece proporcionalmente a la necesidad en aumento de una intervención reguladora del proceso social» ${ }^{131}$.

- «Solamente en la medida en que consigamos llevar al área de la conciencia y de la observación explícita los diferentes puntos de partida y de aproximación a los hechos que son corrientes, (...), podremos esperar (...) controlar las motivaciones y presupuestos inconscientes que, en último término, han traído a la exístencia estos modos de pensamiento. Un nuevo tipo de objetividad en las ciencias sociales es alcanzable (...) por medio del conocimiento crítico y del control de ellas (de las valoraciones)» ${ }^{132}$.

Como vemos, en definitiva, K. Mannheim formula un planteamiento similar al nuestro: al realizar afirmaciones sobre el 'sentido' de los hechos entramos en el campo de las valoraciones, y en ese campo las ideologías, los presupuestos inconscientes o las tendencias personales juegan un gran papel. Una influencia que puede estar presente tanto en la elección de problemas como en la forma de abordarlos, de responderlos y sobre todo de explicarlos. Esas motivaciones y presupuestos, conscientes o inconscientes, diseñan un futuro, por la vía positiva o negativa. Al contrastar al individuo con ese «horizonte» social, observamos si ese lugar diseñado es un lugar de crecimiento y de libertad, de equidad y de justicia, o es más bien una formulación dogmática que, al final, encubre y justifica los intereses y deseos de un colectivo determinado, que absolutiza su interpretación desde el poder (recordemos la conversión del marxismo en una ortodoxia caracterizada por discusiones escolásticas, de la que se expulsa a autores heterodoxos, no sé si inevitable pero sí que indeseable como situación definitiva, como 'utopía' que impulse la dinámica sociopolítica de la sociedad. Volvemos a observar la identificación de la verdad y la bondad con

131. K. MANNheim, Ideología y utopía, Madrid, Aguilar 1966, p. 46.

132. Idem, o.c., p. 50 . 
el orden real existente, identificación duramente criticada por Horkheimer y Adorno.

Es importante resaltar la conexión afectivo-instintual de los pensamientos dogmáticos. La defensa del dogma es, a menudo, una defensa no argumentativa, sino visceral. Esta es la causa de que por 'dogmas' se elimine a la gente, sea como ataques verbales o físicos. La absolutización encuentra un apoyo afectivo y se vuelve despersonalizadora. El hombre tiene una tendencia innata a buscar respuestas seguras, permanentes, absolutas, que le orienten de forma sistemática y absoluta en el marasmo de los fenómenos. Este es uno de los rasgos que explica la existencia de movimientos ideológicos absolutistas, como el fascismo o el comunismo ortodoxo. Esta participación afectiva en una realidad de orden superior es bien visible en ciertas afiliaciones de moda en nuestros días: el 'boom' de las sectas podría ser un magnífico ejemplo... El pensamiento crítico es mucho más difícil de mantener. Sin embargo, «desde un punto de vista sociológico el hecho decisivo de los tiempos modernos (...) es que (...) ha nacido una 'intelligentsia' libre. Su característica principal es que de manera creciente ha sido reclutada en estratos sociales y situaciones vitales constantemente cambiantes, y que su modo de pensamiento no está ya sometido a reglamentación por una organización en forma de casta. A causa de la ausencia de una organización social propia, les ha sido posible a los intelectuales tomar en consideración los modos de pensar y de experimentar que se encontraban en abierta competencia unos con otros» ${ }^{133}$. Una de las conclusiones que hemos de sacar de la pluralidad de puntos de vista, y de la falsedad intrínseca de las verdades definitivas y científicas que según las ideologías expresan y definen el sentido de los hechos, es la siguiente: la fecundidad de un método de investigación nunca nos debe llevar a considerarlo como el único método, como el método con mayúsculas, para el tratamiento de un objeto determinado.

La ideología satisface la necesidad de conferir significación presente en todo ser humano, «es solamente por medio de este conferir significación, de este valorar la definición, por lo que los acontecimientos producen una situación en la que la actividad y contra-actividad son diferenciables, en la que la totalidad de los sucesos puede ser articulada en un proceso" ${ }^{134}$. Pero, al dar un determinado significado, polarizamos el sentido en torno a él, y ocultamos otros posibles, y quizás más reales, significados. La conciencia crítica de la necesidad del proceso de conferir significación, y la conciencia de su carácter propio, es la mayor salvaguarda contra la noche oscura de las ideologías dog-

133. Idem, o.c., p. 57.

134. Idem, o.c., p. 68 . 
máticas. El hombre no puede vivir sin un sentido colectivo y filosófico de la vida, ya le sea dado o ya lo alcance por reflexión personal. Por eso «la política (...) únicamente tiene fundamental significación cuando inculca sus designios con una peculiar filosofía, haciendo uso de su propia concepción. (...) con la creciente democratización (...) los partidos políticos se esforzaron por prevenir sus conflictos con una fundamentación y una sistematización filosófica. Primero el liberalismo; después, a remolque, siguieron su ejemplo los partidos conservadores, $y$, finalmente, el socialismo hizo de sus fines políticos un credo filosófico, una concepción del mundo con métodos bien establecidos de pensamiento y conclusiones prescritas (...). El resultado (...) fue que a cada tipo de política (...) se dio gradualmente un matiz científico» ${ }^{135}$.

Prueba de la dificultad de la racionalidad crítica es la renuncia de la Escuela de Frankfurt a proponer un 'camino' de realización concreta en la praxis. Frente a esta postura, en muchas exposiciones de problemas sociales se hace una y otra vez hincapié en la idea previa a la que se quiere reconducir el análisis. Más aún, quizaś en muchos individuos se vive como realizante el triunfo de una ideología; le da satisfacción vital, olvidando la serenidad reflexiva; todos recordamos euforias colectivas que han desembocado en masacres coletivas, o en incumplimientos sistemáticos. Estas últimas líneas describen un peligro que puede existir, a pesar de que la ideología, en cuanto sistema de pensamiento más o menos cerrado y autosuficiente, independizado de la realidad, que responde por nosotros, enajena al individuo de su propia intimidad, de pensar por sí mismo, y por esta razón el hombre debería huir siempre de caer en sus manos; sin embargo, la posibilidad subsiste, está ahí, y puede hacerse realidad, alienando paradójicamente al mismo hombre que la crea. Recordemos la crítica kantiana: «la ilustración es la liberación del hombre de su culpable incapacidad. La incapacidad significa la imposibilidad de servirse de su inteligencia sin la guía de otro (...). ¡Es tan cómodo no estar emancipado!» ${ }^{136}$.

El pensar crítico nos libera, porque no podemos seguir viviendo de la misma manera cuando analizamos los puntos de partida de los razonamientos, y las características del razonar ideológico. Pero no nos da una respuesta fácil, hemos de pensar y buscar la profundización mediante el esfuerzo personal. Por eso es un pensar eminentemente íntimo y personal. Ojalá todos los ejercicios de reflexión comenzaran por aclarar más sus 'deseos' y la orientación de la que parten: «es evidente que toda diagnosis científico-social está estrecha-

135. Idem, o.c., p. 85.

136. I. KANT, Respuesta a la pregunta: ¿Qué es la Ilustración?, en I. KANT, Filosofía de la historia, México, F.C.E. 1978, p. 25. 
mente relacionada con las valoraciones y las orientaciones inconscientes del observador y que la autoaclaración crítica de las ciencias sociales está íntimamente ligada a la autoaclaración crítica de nuestra orientación en el mundo cotidiano» ${ }^{137}$. El hombre alcanza la objetividad y la individualidad enfrentándose a sí mismo. Aunque parta de una tradición cultural dada, ha de enfrentarse críticamente con lo existente. La ideología, en cuanto sistema cerrado y que requiera identificación afectiva, es una forma despersonalizadora que acaba justificando el poder de una clase o grupo o élite determinada. El análisis de los presupuestos desde los que se elaboran los distintos acercamientos reflexivos a la sociedad nos ayuda a comprender la pluralidad y los factores que hay que tomar en consideración al analizar la cuestión del sentido de los hechos. Y, necesariamente, este análisis crítico nos enfrenta con el problema de las ideologías, del cientifismo y del pensamiento político. De aquí que, tras analizar los conceptos claves de algunos análisis de la sociedad, planteáramos el problema de la ideología. Es conveniente indicar que aquí utilizamos el concepto de ideología en un sentido determinado, 'fuerte', como sistema de pensamiento autosuficiente, que genera mecanismos de identificación afectiva... Indudablemente, nos situamos en un extremo, y no negamos la presencia de elementos ideológicos en el discurso, ni la presencia de identificaciones afectivas o de elementos simbólicos; simplemente, criticamos un exceso de tales elementos, que en una cierta medida, son consubstanciales al hombre.

En último lugar, señalaremos la limitación intrínseca que afecta tanto a la 'ideología' como al pensar 'utópico': ambos enmascaran ciertos aspectos de la realidad social si se absolutizan (ya que, como hemos afirmado antes, un componente ideológico o utópico siempre está presente en la reflexión del hombre. Pero una cosa es la ideología, y otra que haya elementos ideológicos en el pensamiento; una cosa es la utopía y otra que haya elementos utópicos en el pensamiento y en la praxis). La ideología de un grupo, en ciertas situaciones, puede estar tan ligada a una situación por sus intereses que ese grupo no es capaz de ver algunos hechos que harían entrar en crisis tanto su idea de las cosas como la dominación que ejerce sobre ellas. Asimismo, en determinadas utopías observamos que algunos grupos oprimidos están «tan fuertemente interesados en la destrucción y transformación de determinada concepción de la sociedad que, sin saberlo, ven sólo aquellos elementos de la situación que tienden a negarla. Su pensamiento es incapaz de diagnosticar correctamente una condición existente de la sociedad» ${ }^{138}$.

137. K. MANNHEIM, Ideología y utopía, o.c., p. 95.

138. Idem, o.c., p. 89. 


\section{El peligro del dogmatismo}

Hemos analizado algunos puntos claves de los que parte el razonamiento de diversos autores influyentes en las Ciencias Sociales. Al analizar sus propuestas sobre el sentido de la realidad social, hemos resaltado sus aciertos y carencias, así como que la cuestión del 'sentido' es una cuestión abierta, marcada en gran medida por las predisposiciones intelectuales y por el carácter del propio razonamiento de cada uno. Nos hemos detenido en una tendencia implícita en cierto tipo de pensamiento, la tendencia a transformarse en ideología desde una postura inicial de instancia crítica, y hemos intentado sintetizar algunos rasgos y efectos del pensar ideológico. El desarrollo de nuestro estudio nos enfrenta ahora con un peligro implícito en algunas concepciones sobre la realidad, que afectan de manera determinante a las investigaciones llevadas a cabo por los científicos sociales, y que condicionan tanto los problemas que se plantean como la metodología y el valor conferido a las respuestas. Este peligro es el dogmatismo: la ideología tiende, por su propia naturaleza, a convertirse en dogma.

Al observar el influjo de ciertos conceptos en el análisis de la sociedad que llevan a cabo autores como Marx o Horkheimer, y al indicar tanto el proyecto futuro que dichas concepciones nos ofrecen como los límites de su proyecto, de las posibilidades de realización del hombre en el marco que nos brindan, encontramos que cada uno de ellos aborda cierta temática social de forma acertada y brillante. Nos desvelan aspectos que anteriormente no eran tenidos en cuenta. Observamos también que, así como el pensamiento de la Teoría Crítica no formula utopías, otras 'razones' sí las formulan, incluso con carácter científico, y pasan de ser análisis de aspectos a ser el marco teórico al que se tiene que ajustar cualquier análisis teórico de cualquier ciencia social. Es el paso del pensamiento crítico al pensamiento dogmático, dado el mayor grado por ciertos seguidores de algunos de los autores estudiados. Este 'salto' se da en las ciencias sociales porque el análisis de la sociedad en un momento final ha de preguntarse por el 'sentido' de los actos, las obras, los seres humanos y las relaciones entre ellos. Aquí los fundamentos filosóficos del método salen a la luz, como las connotaciones políticas o el concepto de sociedad que tiene el científico social. El problema, a mi modo de ver, no es que exista una relación entre la explicación significativa, la teoría general en la que se 'habita' y la realidad observada, ya que siempre existe una interacción e influencia recíproca, sino que el problema aparece cuando en esa relación se absolutiza un polo, y ya no se establece un diálogo, sino que se establece un monólogo en el que solamente habla una ideología determinada, un pensamiento previo determinado, en el que se predica algo a lo que ha de ajustarse la realidad. Un algo que ya no es consecuencia de la reflexión de un sujeto maduro que observa 
la interrelación entre pensamiento y realidad, sino que es una imposición a ese sujeto desde un pensamiento independizado, y que, por lo tanto, ajeno a dialéctica de la vida, tiende a convertirse en monolítico e inalterable. Se constituye en ortodoxia. Resaltar los elementos inconscientes del lenguaje ideológico, así como el papel del inconsciente en la sociedad, el carácter del instinto y del sentimiento de culpabilidad, el papel de la economía, nos ha de llevar a una concepción más amplia de los fenómenos y a una explicación lo más sintética posible. Y esto siempre dentro de un discurso comunicativo basado en la fundamentación argumentativa y la verificación intersubjetiva de las propuestas que realicemos. El objetivo de este estudio es destacar cómo un análisis social o una concepción de la realidad social ( $y$ por ende una concepción del sentido de la vida) se ve afectada por los presupuestos conscientes o inconscientes de los que parte y que desarrolla un autor determinado, conceptos o ejes que iluminan facetas anteriormente desconocidas, pero que corren el riesgo de convertirse en 'ideologías', abandonando su carácter crítico con respecto a la sociedad. Una mente racional ha de preguntarse por el horizonte de realización, por las posibilidades de crecimiento que le ofrece una antropología basada en un concepto específico de trabajo, o en la concepción del yo como un superviviente de los castigos del super-yo y de los impulsos del ello. Estas cuestiones se formulan cuando el análisis de un determinado problema social nos remite a la fundamentación filosófica del método y de las respuestas otorgadas...

La crítica a las tentaciones de absolutizar una teoría, convirtiéndola en algo atemporal, clave de sentido para toda la historia, se basa en el carácter histórico del sujeto humano: «Sin embargo, el sujeto que responde es también historicidad. Su deber ser sólo puede ser histórico, puesto que la respuesta a la pregunta sobre el sentido de la existencia histórica sólo se puede formular como respuesta de la historicidad, una respuesta en la historia; es, por tanto, una respuesta en el espacio y en el tiempo, y no sub specie aeternitatis. Todas y cada una de las observaciones de Mannheim sobre Marx pueden aplicarse a todas las filosofías de la historia, aunque el mismo problema sea menos evidente en algunos casos. Cualquiera que reflexione históricamente sobre su ser, no puede formular su deber ser como una verdad universal» ${ }^{139}$. Ese salto de un deber ser histórico, relativo y con posibilidad de ser erróneo, a un deber ser universal, atemporal e inmune a toda crítica es el 'salto' característico del pensamiento dogmático.

139. Agnes Heller, Teorfa de la historia, Barcelona, Fontamara 1986, pp. 188-189. 
4. La importancia de la reflexión filosófica sobre las Ciencias Sociales y sus métodos

Al finalizar nuestro análisis, creo que ya es patente la importancia de esa reflexión crítica que saca a la luz las implicaciones conscientes e inconscientes de nuestro pensamiento, y los supuestos que a menudo configuran tanto los análisis como las respuestas que damos a los problemas sociales. La pervivencia de ese pensamiento negativo defendido por la Escuela de Frankfurt es importante para asegurarnos frente a la desfiguración ideológica y dogmática de la realidad. Y es fundamental para que alcancemos a ver el diseño de la sociedad y las claves de realización del ser humano que nos ofrecen las diversas teorías acerca de la sociedad, perspectivas que hemos de analizar y contrastar.

Por otra parte, al poner de manifiesto la importancia de los elementos instintivos en nuestro pensamiento, nos capacitamos para observar y controlar estos elementos, evitando la seducción de las ideas absolutas. En definiti$\mathrm{va}$, se trata de llevar a la práctica una intención de sabor kantiano: conocernos a nosotros, a las teorías desde las que analizamos la realidad (y que podemos superar, en la dialéctica de progresión de la historia), y calibrar el alcance y el rango de las verdades que obtendremos en las Ciencias Sociales, analizando los supuestos, los métodos y el diseño implícito de un horizonte social (de una futura sociedad, de una sociedad más justa, en la que el individuo se realice más plenamente) que nos ofrecen los conceptos básicos de las teorías sobre la sociedad. Hemos tratado de abordar el problema del sentido, de la explicación de los datos a que se ven abocados los científicos sociales, y en cuya definición (la definición del sentido) intervienen las teorías filosóficas y los conceptos que subyacen en la mente del investigador o de un colectivo de científicos sociales determinado.

\section{A. LÓPEZ PELÁEZ \\ Madrid}

